University of Rhode Island

DigitalCommons@URI

Open Access Master's Theses

2014

\title{
EFFECTS OF SOCIAL SUPPORT ON INDIVIDUALS' RESULTS OF 12-WEEKS OF CARDIAC REHABILITATION
}

Danika Korpacz

University of Rhode Island, dkorpacz@uri.edu

Follow this and additional works at: https://digitalcommons.uri.edu/theses

\section{Recommended Citation}

Korpacz, Danika, "EFFECTS OF SOCIAL SUPPORT ON INDIVIDUALS' RESULTS OF 12-WEEKS OF CARDIAC REHABILITATION" (2014). Open Access Master's Theses. Paper 353.

https://digitalcommons.uri.edu/theses/353

This Thesis is brought to you for free and open access by DigitalCommons@URI. It has been accepted for inclusion in Open Access Master's Theses by an authorized administrator of DigitalCommons@URI. For more information, please contact digitalcommons-group@uri.edu. 


\section{EFFECTS OF SOCIAL SUPPORT ON INDIVIDUALS' \\ RESULTS OF 12-WEEKS OF CARDIAC \\ REHABILITATION \\ BY \\ DANIKA KORPACZ}

A THESIS SUBMITTED IN PARTIAL FULFILLMENT OF THE REQUIREMENTS FOR THE DEGREE OF MASTER OF SCIENCE

IN

KINESIOLOGY

UNIVERSITY OF RHODE ISLAND 


\title{
MASTER OF SCIENCE \\ OF \\ DANIKA KORPACZ
}

\section{APPROVED:}

Thesis Committee:

\author{
Major Professor Linda S. Lamont \\ Bryan Blissmer \\ Susan Roush \\ Nasser H. Zawia \\ DEAN OF THE GRADUATE SCHOOL
}

UNIVERSITY OF RHODE ISLAND

2014 


\begin{abstract}
PURPOSE: The purpose of this study was to analyze the effects of social support on an individual's result of 12 -weeks of cardiac rehabilitation. Specifically, this study investigated whether or not participants decreased their body mass index, increased their stress test duration, showed greater changes in their maximum attained heart during their stress test and overall improvements in health through their SF-36 scores. METHODS: Fifty-five men and women from Rhode Island were recruited from The Miriam Hospital Center for Cardiac Fitness. All participants were currently participating in cardiac rehabilitation. They completed all twelve weeks, completed all necessary paperwork and completed a treadmill stress test. This was a descriptive study design that used pre and post testing physiological measurements. The ENRICHD Social Support Instrument (ESSI) was given after the participant completed the consent form. The majority of these participants had high levels of social support $(\mathrm{N}=49)$. Individuals were considered to have high social support if they had a minimum score of 28 out of 34 and were considered to have low social support if they scored at or below 27 out of 34 . Pre test measurements included anthropometrics (body mass index $\left(\mathrm{kg} / \mathrm{m}^{2}\right)$ : high social support $=28.81 \pm 5.07$, lower social support $=26.70 \pm 3.85$, stress test measurements (resting systolic pressure $(\mathrm{mmHg})$ : high social support $=123.10 \pm 16.91$, lower social support $=115.60 \pm 15.06$; resting diastolic pressure $(\mathrm{mmHg})$ : high social support $=73.35 \pm 8.48$, lower social support $=70.00 \pm 9.06$; total time on treadmill $(\mathrm{sec})$ : high social support $=418.83 \pm$ 126.07, lower social support $=391.80 \pm 75.74$; maximum attained heart rate $(\mathrm{bpm})$ : high social support $=119.00 \pm 16.66$, lower social support $=116.00 \pm 19.16)$ and
\end{abstract}


questionnaires (SF-36 mental composite score: high social support $=53.08 \pm 10.53$, lower social support $=50.67 \pm 11.68$; physical composite score: high social support $=$ $39.19 \pm 7.63$, low social support $=36.67 \pm 3.76$ ). RESULTS: The level of social support did not have an impact upon changes in weight, BMI, stress test time and maximum attained heart rate over the course of cardiac rehab enrollment. A generalized linear model showed that those with higher social support reported higher scores on the overall physical composite score $(\mathrm{P}=0.000)$; as well as, the physical functioning $(\mathrm{P}=0.006)$, vitality $(\mathrm{P}=0.047)$ and social functioning $(\mathrm{P}=0.017)$ subscales of the SF-36. CONCLUSION: These results suggest that the level of social support did not have an impact on measured outcomes such as anthropometric data and stress test results. However, there were clear effects when examining the Health Related Quality of Life Measure. The group lower in social support, despite apparent physical improvements on the stress test, actually had declines in the physical composite scale and several specific subscales. This finding warrants further study and replication within a larger sample as it suggests potentially negative outcomes in individuals that are not receiving high levels of support. 


\section{ACKNOWLEDGMENTS}

There are numerous people who significantly assisted me in producing a research study. A special thank you to all of the participants who allowed me to ask them many questions. Additionally, I would like to thank my major advisor, Dr. Linda Lamont for her continued support and guidance throughout the entire process. A special thank you goes to Dr. Peter Tilkemeier who volunteered his time and energy to allow me to complete my research study at The Miriam Hospital. Without his support this project would not have been possible. I would also like to thank all of the staff at The Miriam Hospital Center for Cardiac Fitness for their guidance and support. I would also like to thank Dr. Bryan Blissmer for his assistance with the data analysis and statistics, and Dr. Susan Roush for her contributions to the research study. Finally, I would like to thank my family and friends for encouraging me to always do my best and never give up. 


\section{TABLE OF CONTENTS}

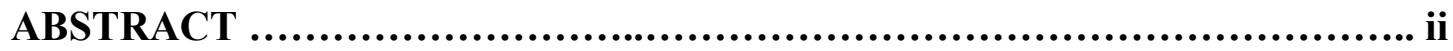

ACKNOWLEDGEMENTS .................................................... iv

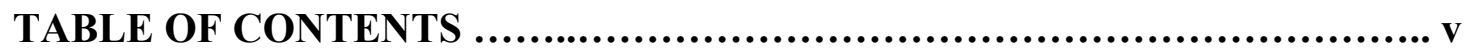

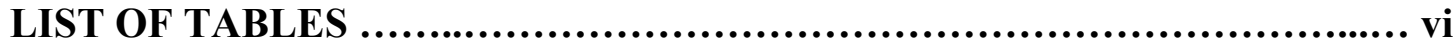

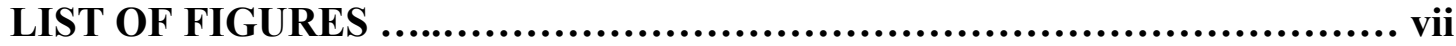

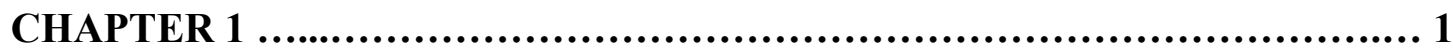

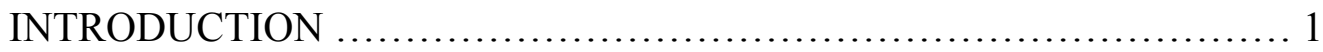

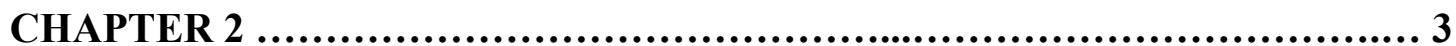

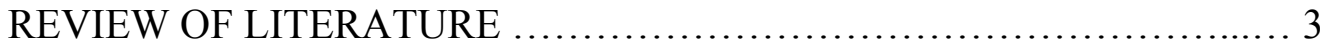

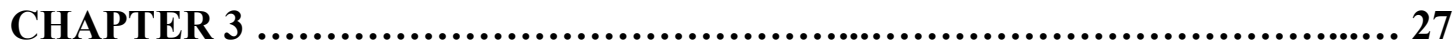

METHODOLOGY ...................................................... 27

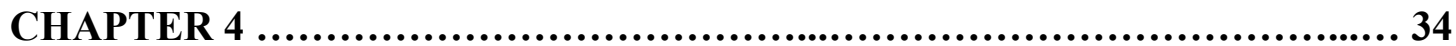

RESULTS ................................................................ 34

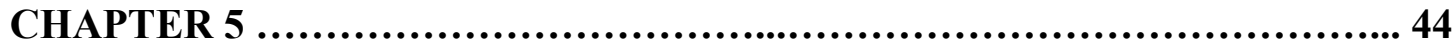

DISCUSSION ........................................................... 44

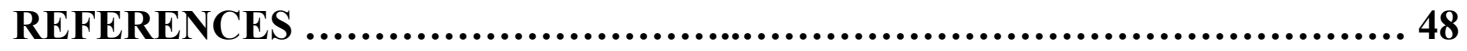

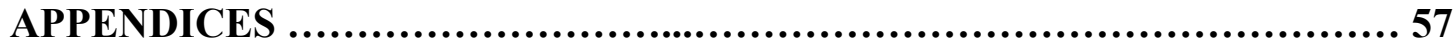

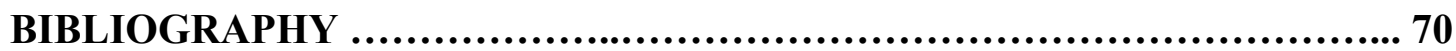




\section{LIST OF TABLES}

TABLE

PAGE

Table 1. Baseline Subject Characteristics of Social Support Groups

Table 2. Body Mass Index, Stress Test Time and Maximum Attained Heart Rate

Results 38

Table 3. SF-36 Mental and Physical Composite Scores Results 40

Table 4. SF-36 Mental and Physical Composite Scores Results 41 


\section{LIST OF FIGURES}

FIGURE

PAGE

Figure 1. ENRICHD Social Support Instrument (ESSI) Cumulative Scores ............. 33

Figure 2. Pre and Post SF-36 Mental and Physical Composite Scores..................... 42

Figure 3. Pre and Post SF-36 Significant Subscale Scores ..................................... 43 


\section{CHAPTER 1}

\section{INTRODUCTION}

An estimated 82 million American adults have one or more types of cardiovascular disease. Of these Americans 400,000 are 60 years of age or older. ${ }^{1}$ Roger, Go, Lloyd-Jones et al. ${ }^{1}$ stated that cardiovascular disease (CVD) has accounted for more deaths than any other cause of death in the United States since the 1900's. According to the American Heart Association (AHA), CVD, also known as heart disease, describes several problems related to the buildup of plaque in the artery walls. ${ }^{2}$ Heart muscle needs oxygen to survive. A heart attack occurs when the blood flow that brings oxygen to the heart muscle is severely reduced or cut off completely. This happens because the coronary arteries that supply the heart with blood can slowly become thicker and harder from a buildup of fat, cholesterol and other substances that together are called plaque. This slow process is known as atherosclerosis. When plaque breaks, a blood clot forms around the plaque that causes a block in the artery that can shut off blood flow to the heart muscle. When the heart muscle is starved for oxygen and nutrients, it is called ischemia. Damage or death of heart muscle occurs as a result of the ischemia, and this is called a heart attack or myocardial infarction. ${ }^{2}$

CVD is more prevalent in our developed country compared to an underdeveloped country because our lifestyle is poor. According to Carlsson, Wändell, Gigante et al. ${ }^{3}$ a healthy lifestyle has repeatedly been shown to have an 
impact on health and longevity in women and men. These factors generally include: being physically active or physically fit, having a healthy diet, being a non-smoker, having a low waist/hip ratio or normal body mass index (BMI), and moderate alcohol consumption. ${ }^{4}$ Many of these risk factors can be classified as modifiable or non-modifiable. The risk factors that are modifiable are hypertension, abnormal blood lipid levels, tobacco use, physical inactivity, diabetes and diet. Age, family history, gender and ethnicity are all considered non-modifiable risk factors because they cannot be changed. ${ }^{5}$

Research has shown that health behavior modification is a dynamic process requiring a tremendous amount of commitment from both the individual and their social support. ${ }^{6}$ Therefore, it has been suggested that close relationships may protect against CVD by shielding stress. Furthermore, the cultivation of extended networks with people sharing similar experiences has been observed to be just as important in CVD protection. ${ }^{7}$ Social support is the resources provided by others and the quality of them. ${ }^{8,9,10}$ Evaluating the perceived level of social support of a patient with CVD may help to modify their risk factors by allowing them to more actively engage in life. ${ }^{6}$ Perceived social support is the amount of support an individual believes is available to them. ${ }^{11}$

Accordingly, this study was created to examine the effects of social support on 12-weeks of cardiac rehabilitation (CR). This study was designed to examine the individuals perceived level of social support using the ENRICHD Social Support Instrument (ESSI). 


\section{CHAPTER 2}

\section{REVIEW OF LITERATURE}

\section{Cardiovascular Disease}

According to the $\mathrm{AHA}^{2}, \mathrm{CVD}$, also known as coronary artery disease (CAD) or heart disease, describes the narrowing and hardening of arteries through plaque buildup. This process is called atherosclerosis and it can lead to angina, or chest pain, the most common symptom of CAD. ${ }^{12}$ Angina or chest pain occurs because of the reduced blood flow to the heart. ${ }^{12,13}$ Gradually, heart disease weakens the heart muscle and decreases the blood flow transporting oxygen to the heart muscle. Possible outcomes may be a myocardial infarction (MI). An MI occurs when part of the heart muscle or myocardium dies or sustains damage due to a lack of oxygen.

CVD is the leading cause of death in the United States of America. ${ }^{1}$ It affects over 100 million people and contributes to 7.2 million deaths each year. ${ }^{14,15,16,17}$ Most of the individuals suffering from CVD are sixty years or older. ${ }^{5}$ Roger, Go, LloydJones et al. ${ }^{1}$ stated that since 1900 cardiovascular disease has accounted for more deaths than any other cause of death in the United States. According to Carlsson, Wändell, Gigante et al. $^{3}$ a healthy lifestyle has a positive impact on health and longevity in both men and women. Factors involved in a healthy lifestyle generally include: being physically active or physically fit, having a healthy diet, being a nonsmoker, having a low waist to hip ratio or normal body mass index (BMI), and moderate alcohol consumption. 
Risk factors for heart disease include high cholesterol, the metabolic syndrome, physical inactivity, diabetes, high blood pressure, being overweight and obese, and tobacco use. ${ }^{2,12,13}$ The non-modifiable risk factors include an individual's age, gender and prevalence of family history. Although they are non-modifiable they may help determine if a patient is inclined to develop pre-CVD. The modifiable risk factors include: high cholesterol, high blood pressure, lack of physical activity, obesity, smoking and diabetes. Even a slight change in some of these risk factors can make a significant difference in the development of CVD. The greater number of major risk factors an individual has, the greater the chance that they will develop CVD. $^{5}$

CVD is often thought of as a disease affecting men more than women. Yet, statistics have shown that CVD, heart attack and stroke are the leading cause of death among women in. It has been said that it converts to nearly 1 death per minute. It has also been found that women who are forty years and older are less likely than men of the same age to survive a year after the heart attack. ${ }^{18}$ Typically women, do not develop heart disease or experience any symptoms until they are older than forty-nine years of age. Once a women reaches the age of sixty-five their risk for CVD surpasses men of the same age. Also, women over the age of sixty-five have a thirty-three percent chance of developing heart disease. ${ }^{19}$

Men may develop their first heart disease symptoms between the ages of thirty-five and forty. Also, men are six and a half times more likely than women between the ages of thirty-nine to forty-nine to have a heart attack. ${ }^{19}$ Symptoms of a heart attack differ greatly between men and women. The symptoms that men incur are 
much more definitive. Women often experience more subtle symptoms than men, which sometimes can lead to a misdiagnosis. Because women experience more subtle symptoms, they often do not undergo the same diagnostic testing that do men. ${ }^{20}$

Roughly 700,000 CVD patients undergo CABG or angioplasty per year. Of these, only thirty-one percent of all PTCA, with and without stents, were performed on women in 2005. Of Medicare patients, men were two to three times more likely than women to receive an implantable defibrillator for prevention of sudden cardiac death. $^{20}$

When an individual is diagnosed with heart disease, they have the option to participate in a CR program, typically within two to six weeks following acute coronary artery disease symptoms and four to eight weeks after coronary artery bypass graft surgery. The CR program typically lasts about three months. ${ }^{19,21}$

\section{Cardiac Rehabilitation}

\section{A. Background}

In 2010, heart disease was projected to cost a total of 109 billion dollars, including health care services, medications, and loss of productivity. ${ }^{2}$ As a result CR programs have been implemented to reduce the cost of CVD especially for those who have undergone cardiac surgery. A typical heart disease patient is sedentary, untrained, deconditioned, or orthopedically limited. The main goal of $\mathrm{CR}$ is to educate the patient on a safe and effective exercise program. Secondary goals are improving aerobic endurance and muscular strength, modifying cardiovascular risk factors, including lowering cholesterol, losing weight, controlling blood pressure, improving blood 
glucose and smoking cessation. ${ }^{22}$ The program concentrates on increasing the patient's cardiovascular endurance and flexibility to enable the patient to return to recreational and vocational activities. ${ }^{23}$

According to the American Association of Cardiovascular and Pulmonary Rehabilitation (AACVPR), individuals with the following medical conditions could benefit from CR: stable angina, myocardial infarction, percutaneous transluminal coronary angioplasty (PTCA), coronary artery bypass graft surgery, chronic stable heart failure, cardiac transplantation, and peripheral artery disease.$^{24}$ The most common conditions seen in CR facilities are stent implantations, MI and coronary artery bypass grafts. ${ }^{22}$

CR is a fairly new form of care within the medical field, and over the past twenty years substantial progresses has been made. ${ }^{24,25} \mathrm{CR}$ is a safe and effective way to treat patients who have experienced cardiac events. ${ }^{12,22,25}$ The overall goal of $\mathrm{CR}$ is for the patient to return to a productive and enjoyable life implementing the learned lifestyle changes. The goal is not to cure, but to improve function based on physical symptoms, decrease the severity of the disease, and to limit CVD progression. These goals are met using physical training to improve aerobic capacity, psychological counseling to improve stress management, nutritional counseling to improve diet, education, and the ability to return to work. ${ }^{9}$ These programs employ a team of exercise physiologists, nurses, cardiologists, dieticians, and behavioral medicine specialists to meet these goals. 
CR is split into a four-phase program. Phase I is an inpatient program. This is the acute stage while the patient is still in the coronary care unit. Phase II is an outpatient program that typically lasts approximately three months. During this time patients attend supervised exercise sessions with exercise physiologists or nurses. Phase III is a maintenance program that can last for as long as necessary. During this time patients attend the outpatient CR program while exercising on their own with close, continued monitoring by an exercise physiologist or nurse. Phase IV is unsupervised exercise where the patients no longer needs medical supervision. ${ }^{22}$

\section{B. Benefits of CR}

Exercise is essential for improving a cardiac patient's physical fitness. Improving a patient's fitness has been shown to enhance a patient's quality of life ${ }^{17,26,27}$ and allow older adults to live independently. An improved exercise capacity is associated with decreased heart rate, systolic blood pressure and myocardial oxygen demand. Other physical benefits observed through CR are increased muscle functioning, decreases in overall body weight, and a reduction in body fat. ${ }^{28}$ Along with an improved health status, increases in muscular strength with resistance training can make everyday tasks, such as carrying the groceries easier, and may allow the elderly to live independently and enjoy an improved quality of life. ${ }^{27}$

The most significant improvements have been recorded among deconditioned individuals, ${ }^{28}$ after a three-month-period of supervised exercise. The most noticeable changes are reported in peak oxygen uptake. ${ }^{27}$ Also 
noteworthy is the decrease in the number of female patients that experience social isolation and anxiety. ${ }^{28}$ Attendance in CR is associated with an overall decreased mortality; however, the patient must make a commitment to CR and their own health to gain the benefits. ${ }^{29}$

Other medical benefits achieved through exercise training include reductions in myocardial ischemia and oxygen demand during physical activities. Nutritional counseling can assist in the prevention and management of obesity, hypertension, dyslipidemia and diabetes. ${ }^{27}$ Finally, it has been shown that "maximum exercise capacity, emotional, physical, and social quality of life; smoking abstinence; and blood cholesterol improved during 12week a cardiac rehabilitation program ${ }^{30,}$ (p. 87).

\section{Factors Influencing CR Attendance}

For an individual to begin $\mathrm{CR}$ and be rewarded with the benefits of participating, a physician or cardiologist must refer them..$^{30,31,32}$ Currently women are less likely to receive referrals to CR than men. ${ }^{30,32}$ Cardiologist and physician opinions have the ability to affect the patient's enrollment in CR; if the their opinion is negative then a patient is less likely to attend a program. ${ }^{33,34}$

Patients are often referred to CR but opt not to attend because of various reasons. According to Evenson and Fleury, ${ }^{35}$ the most common reason patients elect not to attend the program is because of their financial situation. Other reasons identified were work or time conflicts, lack of physician support or referrals, and lack of motivation or commitment. 
Johnson, Weinert and Richardson ${ }^{34}$ found that older adult patients who lived in an urban area and had a higher level of social support were more likely to enroll in CR than those with lower levels of social support. However, it seemed that patients who needed to attend CR the most were often the ones that chose not to participate. These are often individuals who use more health services, have a more complicated illness, and have financial constraints. ${ }^{34}$ Patients who enroll and then drop-out of the program are often younger females who believe that their illness is less severe, but suffer from depression, experience angina, or have had a less invasive cardiac procedure. It is essential to identify these patients because they are in need of support and are at risk of dropping out of CR. It is especially important to enlist the support of those around the patient in order for them to embrace these new challenges. ${ }^{36}$

\section{Social Support}

\section{A. Background}

Numerous studies have indicated that there are significant social support effects on health and well being. ${ }^{4}$ An individual's social support can assist with everyday challenges and improve physical and psychological health. A few of the potential improved health outcomes are: psychological adjustment, improved efficacy, better coping, resistance and recovery to disease and reduced mortality. ${ }^{11}$

There is an increasing amount of evidence suggesting that there is a relationship between social support and CVD. ${ }^{15,37}$ Social support can safeguard against the effects of a stressful event by permitting the 
individual to perceive the event as less stressful. There is a great deal of evidence that social support diminishes the stress experienced by CVD patients during their immediate recovery and it positively affects the patient's long term adjustment, well-being, and health outcomes. A sufficient amount of social support positively influences self-esteem, perceptions of health, mood, and adjustment to CVD. ${ }^{9}$

Typically, three categories are described: social networks, social relationships and social support. Social networks are individuals' everyday contacts including a person's family, friends, co-workers, health professionals, and community resources. Social relationships are the quantity, existence and type of relationships. They provide sources of positive evaluation, and for a sense of control over their environment. These may also provide a sense of worth and lovability and importance. Social support is the resources provided by others and the quality of them. It can also be considered the quantitative description of an individual's social network and how much help they receive. $^{8,9,10}$

According to Sorenson and Wang, ${ }^{38}$ social support is defined as "interpersonal assistance intended to enhance the well-being or protection from adverse life events, (p. 306)" and Moser ${ }^{39}$ defined social support as "the comfort, assistance, and/or information one receives through formal or informal contacts with individuals or groups" (p. 27). However, social support has many definitions 
according to different people. Albrecht and Adelman ${ }^{40}$ defined social support as "verbal and nonverbal communication between recipients and providers that reduces uncertainty about the situation, the self, the other, or the relationship, and functions to enhance a perception of personal control in one's life experience" (p. 19). The National Cancer Institute ${ }^{41}$ states that social support is "a network of family, friends, neighbors, and community members that is available in times of need to give psychological, physical, and financial help." The use of many definitions tends to complicate things because each definition has many advantages and disadvantages.

When defining social support it is also important to think about actual versus perceived support. Actual support is the amount of support an individual actually receives (said and done for them). Perceived support is the amount of support an individual believes is available to them and is available when needed. Perceived support is more commonly used than actual support and it has been found that an individuals' perception of social support is determined by their social environment and personality factors. ${ }^{7}$ For this reason sometimes perceived support is more important than actual because it predicts positive mental health. ${ }^{11}$

The two broad domains of social support are structural and functional. Structural support refers to the size, type, density, and frequency of contact with the network of people surrounding an 
individual. Some examples are the frequency of interactions, the number of close contacts versus peripheral acquaintances, marital status, group or church memberships, and geographic location. ${ }^{7}$

Functional support is the support provided by the social structure. There are five types of functional support and they are instrumental, financial, informational, appraisal, and emotional support. Instrumental support is receiving help to complete tangible tasks. Financial support is receiving economic support. Informational support or feedback is provided in the form of necessary information. Appraisal support is help for evaluating a situation or information for self-evaluation whereas social companionship involves spending time doing various activities or just being with others. ${ }^{42,43}$ Additionally, information is needed when confronting a difficult situation, more specifically being diagnosed with a health problem or illness. These are difficult times and support can be an important factor in these situations. ${ }^{11} \quad$ Emotional support provides the feeling of being loved ${ }^{6}$ and meets the individual's emotional needs. ${ }^{11}$ Frequently, individual's relate this type of support to the term social support because it can increase an individual's mood. ${ }^{11}$ Another commonly used label is tangible support, which describes the types of support that are quantified as instrumental or financial, ${ }^{7}$ which is any material assistance provided by others. This assistance includes, but is not 
limited to driving the individual in need to an appointment, cooking and or possibly cleaning. ${ }^{11}$

There is a direct relationship between social support and a pessimistic health outcome in patients that have chronic health conditions. "In the Alameda County study, a nine year community based prospective study, social support was found to be a determinant of mortality ${ }^{6 \prime}$ (p. 23). The population of individuals with low social support observed in this study were found to have two to three times higher mortality rates when compared to those who have social support. Another study, the Tecumseh Community Health Study researched the connection between social relationships and mortality persisting after adjustments were made for age and other health factors. This study was geared towards all cause mortality. The most common cause of death was ischemic heart disease; this study found a relationship between ischemic heart disease and poor social support. ${ }^{6,44}$ Evaluating social support is crucial to successfully modifying the health behaviors of patients that have CVD. Social support helps these individuals with physical activity, nutritional, and smoking cessation programs which all contribute to whether individuals with CVD will be successful. In another example of the effect of social support, those individuals who had positive support lost more weight than those who did not. ${ }^{6,45,46}$

Furthermore, studies have shown that low perceived social support is a predictor of the progression of CVD. ${ }^{7}$ Additionally, high 
levels of social support have been shown to protect CVD patients from the negative consequences of depression. ${ }^{15}$ Other studies have indicated a decrease in mortality, ${ }^{38,47,48,49,50}$ morbidity ${ }^{47,48}$ and a reduced risk of further progression of CVD. ${ }^{48}$

\section{B. Social Support Outside of CR for Individuals enrolled in CR}

Social support applies to a large network of individuals who assist the patient in their path to success in a time of need. It has been found that support networks vary between men and women. Men have a limited network structure that typically includes their wife, where as women have a larger, more multifaceted network that includes a variety of individuals who have specific roles. It was also recognized that women were more likely to have a confidant relationship and men were more likely to mention their wives as confidants but women typically did not mention their husband. ${ }^{51}$ Women reported more support from their children and friends than males, and they are more likely to provide assistance to their friends. ${ }^{4,16,32,38,51}$

Unfortunately, spouses can affect how their partner changes their health behavior by either controlling or supporting them. ${ }^{34,52}$ This can be beneficial or harmful when participating in CR. McLean and Timmins ${ }^{53}$ determined that spouses/ partners often felt isolated from the information process. If the spouse was included in the informationgiving process then this could significantly increase the level of support between the two individuals. ${ }^{51}$ 


\section{Why Are There So Many Surveys and Questionnaires?}

There are a variety of social support instruments currently being used because the methods used to assess social support are varied due to a lack of clear conceptualization relating to social support and health outcomes. ${ }^{42,54,55}$ Instruments are single or multiple items ${ }^{42,55}$ and ask about different types of categories of social support (i.e. emotional, tangible, informational and instrumental support). ${ }^{54,56}$ The instruments can also ask about different types of social support (i.e. support from spouse versus friends, family, co-workers) ${ }^{57}$ The lack of "gold standard" measures makes it difficult to draw conclusions across different studies. Furthermore, some of the instruments have reliability and validity data while others do not.

\section{Some of The Surveys and Questionnaires Available}

\section{The MOS Social Support Survey}

A brief, self-administered and multidimensional social support survey was developed in the Medical Outcomes Study (MOS). ${ }^{42}$ This study looked at the process and outcomes of patient care including treatable chronic conditions over a two-year longitudinal period. The MOS survey was designed to assess social support. It is a 19-item survey of functional social support that represents multiple dimensions of social support using 5 response possibilities. It includes emotional, informational, tangible, affectionate, and positive social interaction. The MOS 
survey is easy to administer to chronically ill patients due to its simplicity. All of the questions were designed to be short, simple and easy to understand, and are restricted to one idea in each question. $^{42}$

Shelbourne and Stewart ${ }^{42}$ claimed the MOS survey has discriminant, construct, and factorial validity although they do not provide objective data to support this claim. Internal-consistency reliability of the scale scores were estimated using Cronbach's Alpha and were found to be between 0.74 and 0.93 for all support measures. This exceeds a 0.50 standard. ${ }^{42}$

\section{The Social Support Questionnaire (SSQ)}

The SSQ is another measurement tool of social support obtains a score for satisfaction with social support based on the availability and perceived number of social supports. It is a 27 item questionnaire designed to measure perceptions of social support and satisfactions with received social support. Each item has a two-part answer. The first part asks to list all of the people that fit the description of the item and part two asks to indicate how satisfied they are with these people. Hence, each administration of this tool results in two scores: a number score (how many people) and a satisfaction score. ${ }^{58}$

The number scores for the 27 items and mean number of persons listed as supports yielded inter-item correlations 
between 0.35 and 0.71 and the Cronbach's Alpha for internal reliability was 0.97 . The inter-item correlations for the satisfaction scores were between 0.21 and 0.74 and for the total scores between 0.48 to 0.72 with an alpha coefficient of 0.94 . Additionally, test-retest reliability correlation was 0.83 for satisfaction scores and 0.90 for overall number scores. ${ }^{58}$

The concurrent validity of the SSQ was shown through a negative correlation between the number scores, satisfaction scores and depression, anxiety and hostility scores (-0.22 to 0.43). Correlation between overall number scores and satisfaction scores were of $0.34 .^{58}$

\section{Sorenson \& Wang ${ }^{38}$}

Sorenson and Wang measured social support by having the patient's answer one question. The question was, "whom would you rely on in time of trouble?" In order to reduce measurement burden this question was asked. It also yielded interval-level data about the size of the patients' social support group. It is easier for older adults to list individuals who assist them with their tasks rather than attempting to determine the appropriate answer in a survey. The limitation to this measure of social support is that social support is a multi-dimensional concept. The reliability of this instrument could not be analyzed 
because it is a single item measure. Additionally, single item measures have threats to internal and external validity. ${ }^{38}$

\section{Boutin-Foster, $\mathbf{2 0 0 5}^{6}$}

Boutin-Foster developed a two-question questionnaire administered to patients in the hospital with CVD to "identify the categories of instrumental social support that patients with coronary artery disease perceived as being most helpful when attempting to make changes in their lifestyles ${ }^{6 \%}$ (p. 24). The first question asked was, "people who are diagnosed with CAD often have to make changes in their health behaviors. What are some of the changes that you have had to make in an effort to stay healthy?" The second question was, "what are some things that your family members, close friends, coworkers, and health care providers have actually done that you found most helpful in making these changes?"”

Patients were asked these two questions, because it is important to determine the type of instrumental social support that an individual with CAD may have. This is because individuals with a significant amount of instrumental support are perceived to have better success with health behavior modifications. If determined that an individual has instrumental support, it indicates that their support is able to provide and promote better health outcomes. The first question addresses behaviors that were 
specific to CVD, and the second question gave the patient an opportunity to describe their experiences in detail. These questions were also chosen because they did not limit the social network members to family members, but expanded to other types of social network. The questions were chosen based on other theories from studies that had been successful. The questions were specifically chosen to eliminate some of their perceived limitations and restrictions to a specific gender, race, ethnicity, and social support. The reliability of this measure is not known and the questionnaire is being further developed and validated. ${ }^{6}$

\section{Perceived Social Support Scale (PSSS)}

The PSSS was developed to measure the extent to which an individual perceives information, feedback and support from friends and family. The PSSS is a 20 item scale to which the individual answers "Yes, No or Don't Know." The items are score 0 for "No," 1 for "Yes" and an answer of "Don't Know" is not scored. Scores range from 0 to 20 with higher scores indicating maximum perceived social support provided from friends and family. This survey has an internal consistency of 0.90 for the friends subscale and 0.88 for the family subscale.$^{59}$

Procidano and Heller ${ }^{59}$ claimed the PSS survey has construct validity although they do not provide objective data to support this claim. 


\section{ENRICHD Social Support Instrument (ESSI)}

The Enhancing Recovery in Coronary Heart Disease (ENRICHD) study was a large, randomized, multicenter trial, that assessed whether morbidity or mortality would be reduced by a psychosocial intervention in people hospitalized for an acute myocardial infarction associated with depression and low social support. The ESSI is a seven-item, selfreported measure used in the ENRICHD trial. The ESSI identified items regarding structural, instrumental and emotional support, which have all been found to be predictive of mortality in CVD patients. The categories were modified from the Medical Outcomes Survey. ${ }^{60}$ Individual items are then summed for a total score, with higher scores indicating greater social support. ${ }^{48}$ The internal consistency of the ESSI using Cronbach's alpha was found to be 0.88 . The inter-item correlations was significant with a $\mathrm{P}<0.001$. Concurrent and predictive validity was assessed using the correlation between ESSI total score and the SF-36 social functioning subscale was significant $(\mathrm{P}=0.002$ and $\mathrm{r}=0.19){ }^{48}$

\section{E. ENRICHD Social Support Instrument (ESSI)}

Psychosocial dysfunction is common in patients undergoing CR, and dysfunction presents itself in the form of depression, anger, anxiety 
disorders, and social isolation. Studies have shown associations between psychosocial disorders and the risk of initial or recurrent cardiovascular events. The ENRICHD study, assessed whether morbidity or mortality would be reduced by a psychosocial intervention in people hospitalized for an acute myocardial infarction associated with depression and low social support. Treatment for depression was provided, when indicated, through cognitive behavioral therapy and selective serotonin reuptake inhibitors. ENRICHD study did not improve reoccurrence of an additional cardiac event, but depression and social isolation improved in the intervention and control groups. Even if psychosocial interventions ultimately are not shown to alter the prognosis of the coronary heart disease patient, they remain an integral part of cardiac rehabilitation to improve the psychological well-being and quality of life of cardiac patients..$^{27,47}$

The ESSI was "originally developed to assess social support among post-myocardial infarction patients, including the availability of instrumental aid and emotional support. The ESSI was chosen because of its high test-retest reliability, good convergence with standard emotional support measures, and its link to cardiac outcomes. The ESSI is also recommended for use when a short screening instrument is desired, as in the case of this study ${ }^{48,}$ (pg. 92-93). The ESSI was also developed to accommodate a demographically, medically, and psychiatrically diverse population. ${ }^{47}$ 


\section{Quality of Life}

Another important aspect of cardiac rehabilitation programs is the assessment of perceived health status at the beginning of the program to tailor the individual's program and at the completion of the program to evaluate improvements. The SF-36 health survey is often used to measure an individual's perceptions of health. Frequently the terms perception of health, health-related quality of life, quality of life and health perceptions are used interchangeably. It has been suggested that quality of life is modifiable and can influence recovery and health behaviors. An improvement in an individual's quality of life could assist in health behavior modifications and ultimately improve their quality of life, as well. ${ }^{61}$

Health-related quality of life should become a more widely used measure in CR programs because it has been found to explain more of the variance in clinical outcomes between CVD patients. Due to the potential of an increase in life expectancy understanding aspects related to quality of life in addition to quantity of life become imperative. An increase in understanding in an individual's quality of life could potentially improve a professional's decision in regards to those requiring an increase of health related care. ${ }^{62}$

Quality of life describes a wide-range of concepts including health in addition to financial status, standards of living and other aspects of life. "Health related quality of life represents the effects of an illness and its treatment as perceived by the patient. It is modified by many factors, including impairment caused by the disease, psychosocial stress and social support ${ }^{63 \prime}$ (p. 83). 
Individuals have been found to have an increased mortality risk post-MI if they lack social support, live alone or have not been married. Individuals with CVD also have an increased risk for a disruption in their social network or social support organization because of their new CVD diagnosis. This disruption could affect their quality of life. A complication in social support could decrease their perceived social support, which could increase the number of physiological and psychological problems. Ultimately an increase in understanding of how quality of life relates to social support could decrease the number of individuals who may experience a poor recovery or an unsuccessful rehabilitation experience. ${ }^{62}$

An individual who has low social support has an increased risk of cardiovascular disease. Therefore, CVD patients with a lack of perceived social support are often strongly associated with low health-related quality of life regardless of risk factors and the severity of their disease. ${ }^{62,63}$ Furthermore, different types of social support show different effects on an individual's quality of life, however, perceived social support has the strongest influence on health related quality of life. In addition to quality of life, an individual's perceived level of social support can affect the development and clinical outcomes of CVD. ${ }^{63}$

\section{Conclusion}

CVD is the leading cause of death in the United States. ${ }^{1}$ Risk factors for heart disease include high cholesterol, metabolic syndrome, physical inactivity, diabetes, high blood pressure, being overweight and obese, and tobacco use., ${ }^{2,12,13}$ When an individual is diagnosed with heart disease, they may be offered the option to participate in a $\mathrm{CR}$ program. ${ }^{21}$ Currently, the following medical 
conditions are thought to benefit from cardiac rehab: stable angina, MI, PTCA, $\mathrm{CABG}$, chronic stable heart failure, cardiac transplantation, and peripheral artery disease. $^{24}$

$\mathrm{CR}$ is a medically supervised program to help patients recover from a cardiac event. It often employs a team of exercise physiologists, nurses, cardiologists, dieticians, and behavioral medicine specialists to recover from cardiac events and to reduce the risk of CVD from occurring and improve the functional capacity and quality of life of the individual. ${ }^{31}$ The goals of CR are to educate, improve the aerobic endurance and muscular strength, modify risk factors, lower cholesterol, lose weight, control blood pressure, improve glucose levels, and smoking cessation, as well as, regaining the ability to return to recreational and vocational activities. ${ }^{9,22,23,24}$ These goals are achieved by attending CR which includes physical activity, education, nutritional counseling, as well as, behavioral medicine counseling.$^{31}$

CR has a significant number of benefits; it can enhance a patient's quality of life, allow older individuals to live independently again, decrease heart rate, systolic blood pressure, oxygen demand, weight or fat reduction, increase muscle functioning and improve tasks associated with activities of daily living, including but not limited to carrying groceries, bathing or cooking. Nutritional counseling is also available during CR. Speaking with a nutritionist can help prevent and manage obesity, hypertension, dyslipidemia and even diabetes. ${ }^{17,26,27,28}$

Another important predictor of success within the CR program is attendance. Patients must be referred in order to attend, which can sometimes 
hinder their enrollment especially if the physician or cardiologist does not have a positive view of the program. Some other reasons patients chose not to attend are financial issues, time, and lack of motivation or commitment. Patients who fail to complete the twelve-week program are typically younger people, women, those who believe their illness is less severe, those who suffer from depression or have stents. $^{33,34,35}$ Therefore, for patient success, it is important to gather enough information to support them throughout the program. ${ }^{36}$

If patients obligate to attend every $\mathrm{CR}$ session then these behavior changes could potentially become part of their new lifestyle. New friendships can be formed with other patients and with the CR staff. CR programs have the ability to educate patients about healthy lifestyles and give them the tools to implement the newly learned lifestyle outside of the program and to sustain these modifications. If the patient encounters a difficult task or challenge they will be able to share their experiences and obtain the necessary support to succeed in cardiac rehabilitation.

Social support is a complex construct that is difficult to define in a clear manner. Often times the source of social support is from an individual's immediate support system consisting of, but not limited to, their spouse, family, friends, and co-workers. Support has been found to have a positive effect on restoring health, especially after a cardiac event. Social support often serves as a safeguard between psychological distress and health outcomes; therefore, significantly enhancing recovery, reducing morbidity and mortality. Social support is a construct applied by a large network of individuals assisting the patient. However, social support varies significantly between men and women. Men have 
a smaller, more limited network typically consisting of only their spouse, while women have a larger, more multifaceted network with a larger variety of individuals who have specific roles. Women often reported that they received more support from their children and friends than men. Women also have more depressive and anxiety symptoms, as well as less social support, and less selfefficacy. $^{16}$

An extensive variety of social support instruments are used to analyze an individual's perceived level of social support. There are a large number of instruments because there is an overall lack of clear conceptualization related to social support and health outcomes. This is most likely because there is no "gold" standard instrument. Therefore, the different instruments may have a single item or multiple items, ask questions from different categories relating to social support, and about different types of social support. This often makes it very difficult to draw conclusions across studies . ${ }^{42,54,55,56,57}$

Taking into account the complexity and multifaceted structure of CR programming, it is extremely difficult to create a standard to apply to every patient. Therefore, it is crucial to stay involved with the patient throughout the program. It is essential to oversee the support a patient receives in order for them to succeed. 


\section{CHAPTER 3}

\section{METHODOLOGY}

Subjects: The participants were men and women from Rhode Island who were referred to an outpatient CR program from March 2013-March 2014. Participants were recruited through The Miriam Hospital Center for Cardiac Fitness. All participants were currently participating in CR. The inclusion criteria were: completing all twelve-weeks of $\mathrm{CR}$, a stress test and the clinical intake paperwork. Exclusions included any participants who un-enroll in the program, did not participate in a pre-CR stress test, could not read or speak English, or chose not to participate.

Cardiac Rehabilitation: At the Miriam Hospital Center for Cardiac Fitness CR is a phase II, medically supervised program combining physical conditioning with nutrition education and behavior modification to reduce the risk factors that are associated with CVD. The program is administered by exercise physiologists and nurses and is directed by a board-certified cardiologist. The 12-week exercise program meets three times per week for approximately 1 hour and 30 minutes each session. Each session includes exercise and an education class. The participant will attend 36 different education sessions ranging from risk factor modification, medications, home exercise, and nutrition to stress management. ${ }^{31}$ 
Once a participant enrolls in the program they undergo a clinical intake that includes a review of their medical, cardiac and exercise history. All participants were risk stratified according the AACVPR guidelines as low, moderate or high risk. ${ }^{31}$

Before the participants began CR they had to have performed a treadmill stress test. A treadmill stress test was administered to calculate the patient's exercise prescription using their maximum achieved heart rate. Their target heart rate was calculated using the Karvonen's equation or $70-85 \%$ of their maximum. The exercise prescriptions were tailored to each participant based on their rating of perceived exertion while exercising and taking other medical problems into account such as peripheral vascular or artery disease, diabetes, gout and any orthopedic limitations. However, there were participants who did not participate in an exercise stress test before beginning the program. If a patient did not complete an exercise stress test then their exercise prescription was solely based on their rating of perceived exertion during each exercise session, the participants were monitored for blood pressure, heart rate measurements, and rating of perceived exertion. ${ }^{31}$

Study Design: This research project was a descriptive pre and post study design that had no control group. Once the participants were identified as possible subjects they were spoken to about being recruited for the study. Once recruited the participants signed the consent form and completed the ENRICHED Social Support Instrument (ESSI). All measures tested at baseline were repeated post-CR. Pre-, during and post measures were as follows: 
1. Pre-measures (identified during the first week of CR): age, gender, diagnosis, left ventricular ejection fraction, diabetes, lipid profile, a1c, total cholesterol, High density lipoprotein (HDL), low density lipoprotein (LDL), triglycerides, cholesterol ratio, height, weight, body mass index (BMI), stress test protocol, total time on treadmill, resting blood pressure, maximal attained heart rate, short-form 36 information.

2. During (usually during the first two weeks of CR): All participants completed the consent forms and ESSI once during the 12-weeks of CR

3. Post-measures: The same measures from the pre-measures were used.

Measurements: The anthropometric measures used in this study were the subject's height, weight and BMI. Height was measured in inches by what the patient tells the staff member during their initial intake session. Weight was measured in pounds with either a Detecto or Health-o-Meter Scale. Both measures were converted to metric units. BMI $\left(\mathrm{kg} / \mathrm{m}^{2}\right)$ was determined using the patient's predetermined height and weight using a computer generated formula (Scott Care's VersaCare program).

The stress test measurements used in this study were treadmill time and maximal attained heart rate. Total time on treadmill is recorded as the amount of time (seconds) that a patient is on the treadmill for the exercise test. The treadmill test protocol was varied and was assigned by the Registered Nurse supervising the test. 
The maximum heart was obtained while completing the stress test on the Quinton Stress Test treadmill while simultaneously being monitored with a 12-lead EKG. The resting blood pressure was obtained before the patient began exercising. The blood pressure was taken after sitting for approximately five minutes in either their left or right arm using a Welch Allyn cuff and a Littman Stethoscope.

The questionnaires used in this study were the ENRICHD Social Support Instrument (ESSI) and the 36-item Short Form Health Survey (SF-36). The ESSI was given to the patient once during their twelve weeks of $\mathrm{CR}$, usually during the first two weeks, but after they had completed their consent form. The SF-36 is a generic measure of health status. The thirty six items cover eight categories including: social functioning, physical functioning, role-emotional, role-physical, mental health, bodily pain, vitality, and general health.

Statistical Analysis: I used Statistical Package for the Social Sciences (SPSS) version 21.0 to analyze our data. The majority of participants had very high levels of social support as seen in Figure 1 (Mean= 31.36 \pm 3.43 ; Median= 33.00; Range= 1934). ESSI scores range from 8-34 with higher scores representing a higher level of perceived social support. Out of the fifty-five participants, twenty-two scored a perfect score of 34; and eleven others scored a near perfect score of 32 or 33 . These participants accounted for a total $60 \%$ of the entire sample; therefore, making a median split not feasible. Participants also did not score below 19. According the ENRICHD study protocol participants are considered to have "low perceived social support if they score a 2 or less on at least two items, excluding item \#4 (help with 
chores); or a score of 3 or less on two items, excluding items \#4 and 7 (before help with chores and marital status) and a total score of 18 or less on items 1, 2, 3, 5, and $6{ }^{47}$

Due results of the total sample, which included many individuals with highperceived social support, I did not have any participants fall into the ENRICHD study protocol for individuals with low social support. In order to create two groups for the study I had to create a criterion in order to make a low social support group. Therefore, to examine the differences I created two groups depending on the total score of the ESSI. Individuals were considered to have higher social support if they had chosen "most of the time" on items 1-6 and that they were married or living with a partner; therefore, giving them a minimum score of 28 out of 34 (Mean $=32.33 \pm 1.96$; Range $=28-34$ ). Individuals were considered to have lower social support if they

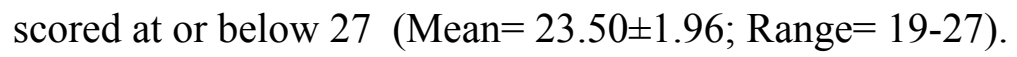

I chose to create these groups because individuals who chose "most of the time" or a 4 out of 5 on items 1-6 of the ESSI are considered to have high perceived social support regardless of their total score. For the purposes of this study, individuasl who report social support "most of the time" through out their life were considered to be in the high perceived social support group. According to Greco, Steca, Pozzi, et al. ${ }^{64}$ "perceived social support from relatives and friends promotes more efficacious coping with illness and easier recovery from sugery" (p. 222). Therefore, individuals do not have to have perfectly perceived social support to cope better with their illness, they just need to perceive it better. Additionally, Greco, Steca, Pozzi, et al. ${ }^{64}$ "found that different indicators of illness severity, such as number 
of diseased vessels, congestive heart failure, and ejection fraction, were predictors of perceived social support” (p. 222).

With the data I ran a series of repeated measures multivariate analysis of covariance (MANCOVA) tests using two time points (pre and post) to test for within subjects effects and social support groups for been subjects effects while controlling for gender. Significance was based on an alpha of 0.05 and a $95 \%$ confidence interval. All data are reported as mean \pm the standard deviation.

The Institutional Review Board at The Miriam Hospital approved this study on July 2, 2013 (IRB Committee \# 2077-13) and The University of Rhode Island on September 13, 2013 (IRB Project \# 466583-1,2,3,4) with an IRB Authorization Agreement signed between the two agencies on September 3 and 5, 2013. 
Figure 1: ENRICHD Social Support Instrument (ESSI) Cumulative Scores

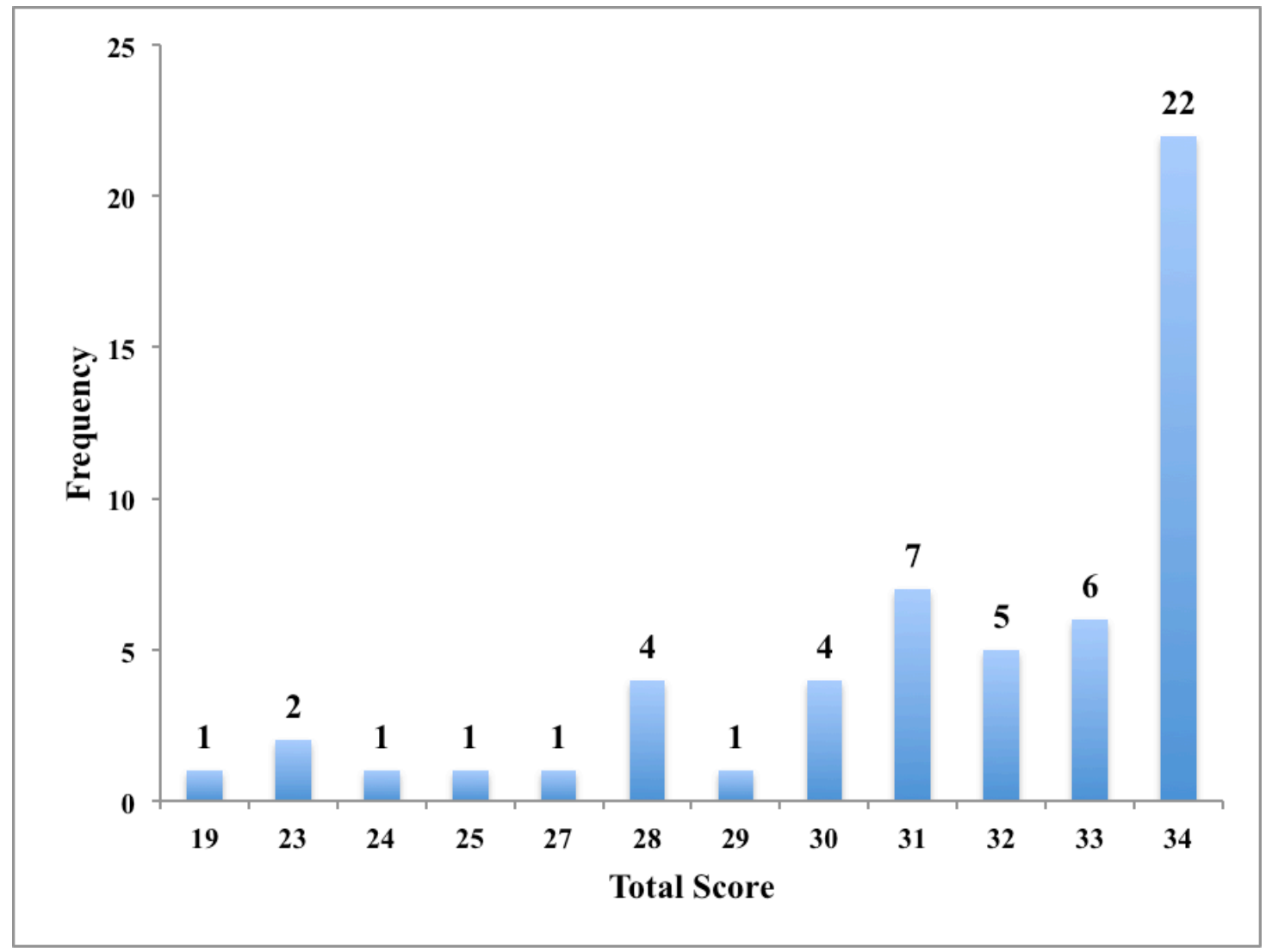




\section{CHAPTER 4}

\section{RESULTS}

A total of 114 subjects were recruited for this study. Seven individuals chose not to participate and 107 individuals consented to participate. 31 participants were terminated due to protocol non-compliance and 21 were terminated due to study termination. Therefore, 55 adults participated in this study. All participants were made familiar with the study protocol before participating and consenting to the study.

The high perceived social support group had a total of forty-nine participants; nine were female and forty were male. Their age was $66.39 \pm 9.21$ years, weight was $87.21 \pm 15.75$ kilograms and BMI was $29.45 \pm 5.45 \mathrm{~kg} / \mathrm{m}^{2}$. The lower perceived social support group had a total of six participants; four were female and two were male. To examine for gender differences between high and lower social support groups a Pearson's Chi-Square test was completed $\left(\mathrm{X}^{2}=6.909\right.$ and $\left.\mathrm{P}=0.009\right)$. There age was $64.67 \pm 13.23$ years, weight was $68.85 \pm 15.67$ kilograms and BMI was $26.35 \pm 3.55$ $\mathrm{kg} / \mathrm{m}^{2}$. Additionally, the high perceived social support group had twenty-two participants whose main diagnosis was MI, two who had angina, seven who had coronary artery bypass graft surgery, thirteen who had a PTCA and five who had a valve replacement or repair. The lower perceived social support group had four participants who had an MI, one who had congestive heart failure, one who had a PTCA and another who had a valve replacement or repair. Using a Independent Samples T-Test I determined the significance of the age $(\mathrm{P}=0.115)$, height $(\mathrm{P}=0.822)$, 
BMI $(\mathrm{P}=0.261)$ and primary diagnosis $(\mathrm{P}=0.007)$ between the groups (Table 1$)$.

I ran a repeated measures multivariate analysis of covariance using two time points (pre and post) and social support group on weight, BMI, blood pressure, and treadmill stress test outcomes. There were no time by group interactions for any of the variables measured weight $(F(1,3.142)=0.927, \mathrm{P}=0.341)$, $\mathrm{BMI}(\mathrm{F}(1,0.075)=0.006$, $\mathrm{P}=0.939)$, systolic pressure $(\mathrm{F}(1,81.706)=0.499, \mathrm{P}=0.484)$, diastolic pressure $(\mathrm{F}(1$, $64.097)=1.305, \mathrm{P}=0.259)$, time on treadmill for stress test $(\mathrm{F}(1,3496.486)=0.550, \mathrm{P}=$ $0.462)$ and maximum attained heart rate while on the treadmill $(F(1,5.714)=0.056, P=$ 0.813). Results also indicated there was no multivariate time main effect within subjects using Wilks' Lambda $(\mathrm{F}(6,39)=0.543, \mathrm{P}=0.722)$. All of these data are represented in Table 2 .

A repeated measures multivariate analysis of covariance using two time points (pre and post) by social support group while controlling for gender was completed using the composite scores of the SF-36. There was a significant multivariate main effect for time by social support group interaction (Wilks' Lambda $(F(2,36)=7.852$, $\mathrm{P}=0.000$ ). Univariate analyses indicated there was no interaction for the mental composite score $(\mathrm{F}(1,0.007)=0.000, \mathrm{P}=0.990)$ but the physical composite score $(\mathrm{F}(1$, $317.00)=14.630, \mathrm{P}=0.000$ ) varied by social support group over time (see Table 3 ).

The SF-36 composite score data is illustrated in Figure 2. The data indicates that the individual's with high and lower social support showed no changes in score on the mental composite score pre to post CR. Individual's with high social support went from $53.08 \pm 10.53$ to $53.62 \pm 9.46$ and individual's with lower social support went from $50.67 \pm 11.68$ to $49.67 \pm 14.29$. Additionally the data indicates that individuals 
with high social support showed significant improvement in their physical composite score versus those with lower social support. Individuals with high social support went from $39.19 \pm 7.63$ to $48.43 \pm 6.03$ and individual's with lower social support appeared to have a slight decline from $36.67 \pm 3.76$ to $32.00 \pm 5.00$.

To tease apart the interactions found above, another repeated measures multivariate analysis of covariance was run using all of the SF-36 subscales. Again, there was a significant time by social support group multivariate interaction (Wilks' Lambda $(F(8,31)=2.558, P=0.029)$. Univariate analyses indicated that many of the subscales did not have a time by social support group interaction including role physical $(\mathrm{F}=3.490, \mathrm{P}=0.069)$, bodily pain $(\mathrm{F}=3.453, \mathrm{P}=0.071)$, general health $(\mathrm{F}=$ 0.261, $\mathrm{P}=0.612)$, role emotional $(\mathrm{F}=0.098, \mathrm{P}=0.017)$ and mental health $(\mathrm{F}=0.114$, $\mathrm{P}=0.738$ ). However, the interaction was significant for measurements of physical functioning $(\mathrm{F}=8.425, \mathrm{P}=0.006)$, vitality $(\mathrm{F}=4.208, \mathrm{P}=0.047)$, and social functioning $(F=6.192, P=0.017)$ (See Figure 3). (See Table 4$).$ 
Table 1: Baseline Subject Characteristics of Social Support Groups

\begin{tabular}{|c|c|c|c|c|c|c|}
\hline & & High & Lower & Total & Significance & \\
\hline & Sample & 49 & 6 & 55 & & \\
\hline \multirow{3}{*}{ Gender } & Female & 9 & 4 & 13 & \multirow{2}{*}{$\mathrm{P}=0.009$} & \multirow{2}{*}{$\begin{array}{c}\chi^{2}= \\
6.909\end{array}$} \\
\hline & Male & 40 & 2 & 42 & & \\
\hline & Age (years) & $\begin{array}{c}66.39 \\
\pm \\
9.21\end{array}$ & $\begin{array}{c}64.67 \\
\pm \\
13.23\end{array}$ & & $\mathrm{P}=0.115$ & $\begin{array}{c}\mathrm{t}=- \\
0.412\end{array}$ \\
\hline \multirow{2}{*}{ Anthropometrics } & Weight (kg) & $\begin{array}{c}87.21 \\
\pm \\
15.75\end{array}$ & $\begin{array}{c}68.85 \\
\pm \\
15.67\end{array}$ & & $\mathrm{P}=0.882$ & $\begin{array}{c}t=- \\
2.696\end{array}$ \\
\hline & $\begin{array}{r}\text { BMI } \\
\left(\mathrm{kg} / \mathrm{m}^{2}\right)\end{array}$ & $\begin{array}{c}29.45 \\
\pm \\
5.45\end{array}$ & $\begin{array}{c}26.35 \\
\pm \\
3.55\end{array}$ & & $\mathrm{P}=0.261$ & $\begin{array}{c}t= \\
0.261\end{array}$ \\
\hline \multirow{6}{*}{ Diagnosis } & MI & 22 & 4 & 26 & \multirow{6}{*}{$\mathrm{P}=0.007$} & \multirow{6}{*}{$\begin{array}{c}\mathrm{t}=- \\
1.404\end{array}$} \\
\hline & $\mathrm{CHF}$ & 0 & 1 & 1 & & \\
\hline & Angina & 2 & 0 & 2 & & \\
\hline & CABG & 7 & 0 & 7 & & \\
\hline & $\begin{array}{c}\text { PTCA w/ } \\
\text { Stent } \\
\end{array}$ & 13 & 1 & 14 & & \\
\hline & Valve $\mathrm{R} / \mathrm{R}$ & 5 & 0 & 5 & & \\
\hline
\end{tabular}


Table 2: Body Mass Index, Stress Test Time and Maximum Attained Heart Rate Results

\begin{tabular}{|c|c|c|c|c|c|c|c|}
\hline & & & & & st of W & in-Subjects & \\
\hline \multirow{2}{*}{\multicolumn{2}{|c|}{ Measure }} & \multicolumn{2}{|c|}{$\begin{array}{l}\text { Type of Social } \\
\text { Support }\end{array}$} & \multicolumn{2}{|c|}{ Time } & \multicolumn{2}{|c|}{ Time*Social Support } \\
\hline & & High & Lower & $\mathrm{F}$ & $\begin{array}{l}\text { Signifi } \\
\text { cance }\end{array}$ & $\mathrm{F}$ & $\begin{array}{l}\text { Signifi } \\
\text { cance }\end{array}$ \\
\hline \multirow{2}{*}{ Weight } & Pre & $\begin{array}{l}86.00 \\
\pm \\
14.08\end{array}$ & $\begin{array}{c}72.25 \\
\pm \\
14.82\end{array}$ & \multirow{2}{*}{$\begin{array}{c}F(1, \\
3.142)= \\
0.927\end{array}$} & \multirow{2}{*}{$\begin{array}{c}\mathrm{P}= \\
0.341\end{array}$} & \multirow{2}{*}{$\begin{array}{c}\mathrm{F}(1,2.721)= \\
0.802\end{array}$} & \multirow{2}{*}{$\begin{array}{c}\mathrm{P}= \\
0.375\end{array}$} \\
\hline & Post & $\begin{array}{l}85.70 \\
\pm \\
14.10\end{array}$ & $\begin{array}{c}71.38 \\
\pm \\
12.64\end{array}$ & & & & \\
\hline \multirow{2}{*}{$\begin{array}{c}\text { BMI } \\
\left(\mathrm{kg} / \mathrm{m}^{2}\right. \\
)\end{array}$} & Pre & $\begin{array}{c}29.45 \\
\pm \\
5.45\end{array}$ & $\begin{array}{c}26.35 \\
\pm \\
3.55\end{array}$ & \multirow{2}{*}{$\begin{array}{c}F(1, \\
0.075)= \\
0.006\end{array}$} & \multirow{2}{*}{$\begin{array}{c}\mathrm{P}= \\
0.939\end{array}$} & \multirow{2}{*}{$\begin{array}{c}\mathrm{F}(1,3.304)= \\
0.257\end{array}$} & \multirow{2}{*}{$\begin{array}{c}\mathrm{P}= \\
0.615\end{array}$} \\
\hline & Post & $\begin{array}{l}29.43 \\
\pm \\
8.12\end{array}$ & $\begin{array}{c}25.98 \\
\pm \\
2.71\end{array}$ & & & & \\
\hline \multirow{2}{*}{$\begin{array}{c}\text { Systoli } \\
\text { c } \\
(\mathrm{mmH} \\
\mathrm{g})\end{array}$} & Pre & $\begin{array}{c}123.10 \\
\pm \\
16.91\end{array}$ & $\begin{array}{c}115.60 \\
\pm \\
15.06\end{array}$ & \multirow{2}{*}{$\begin{array}{c}\mathrm{F}(1, \\
300.264)= \\
1.832\end{array}$} & \multirow{2}{*}{$\begin{array}{c}\mathrm{P}= \\
0.183\end{array}$} & \multirow{2}{*}{$\begin{array}{c}F(1, \\
81.706)= \\
0.499\end{array}$} & \multirow{2}{*}{$\begin{array}{c}\mathrm{P}= \\
0.484\end{array}$} \\
\hline & Post & $\begin{array}{c}122.76 \\
\pm \\
11.06\end{array}$ & $\begin{array}{c}117.20 \\
\pm \\
5.93\end{array}$ & & & & \\
\hline \multirow{2}{*}{$\begin{array}{l}\text { Diastol } \\
\text { ic } \\
(\mathrm{mmH} \\
\mathrm{g})\end{array}$} & Pre & $\begin{array}{l}73.35 \\
\pm \\
8.48\end{array}$ & $\begin{array}{c}70.00 \\
\pm \\
9.06\end{array}$ & \multirow{2}{*}{$\begin{array}{c}F(1, \\
48.645)= \\
0.991\end{array}$} & \multirow{2}{*}{$\begin{array}{c}\mathrm{P}= \\
0.325\end{array}$} & \multirow{2}{*}{$\begin{array}{c}F(1, \\
64.097)= \\
1.305\end{array}$} & \multirow{2}{*}{$\begin{array}{c}\mathrm{P}= \\
0.259\end{array}$} \\
\hline & Post & $\begin{array}{c}72.48 \\
\pm \\
6.81\end{array}$ & $\begin{array}{c}72.80 \\
\pm \\
5.93\end{array}$ & & & & \\
\hline \multirow{2}{*}{$\begin{array}{l}\text { Tread } \\
\text { mill } \\
\text { Time } \\
(\mathrm{sec})\end{array}$} & Pre & $\begin{array}{c}418.83 \\
\pm \\
126.07\end{array}$ & $\begin{array}{c}391.80 \\
\pm \\
75.74\end{array}$ & \multirow{2}{*}{$\begin{array}{c}F(1, \\
104.791)= \\
0.016\end{array}$} & \multirow{2}{*}{$\begin{array}{c}\mathrm{P}= \\
0.462\end{array}$} & \multirow{2}{*}{$\begin{array}{c}F(1, \\
3496.486)= \\
0.550\end{array}$} & \multirow{2}{*}{$\begin{array}{c}\mathrm{P}= \\
0.462\end{array}$} \\
\hline & Post & $\begin{array}{c}513.7 \pm \\
150.79\end{array}$ & $\begin{array}{c}503.40 \\
\pm \\
89.80\end{array}$ & & & & \\
\hline
\end{tabular}




\begin{tabular}{|c|c|c|c|c|c|c|c|}
\hline \multirow{2}{*}{$\begin{array}{l}\text { Max } \\
\text { Heart } \\
\text { Rate } \\
\text { (bpm) }\end{array}$} & Pre & $\begin{array}{c}119.00 \\
\pm \\
16.66\end{array}$ & $\begin{array}{l}116.00 \\
\quad \pm \\
19.16\end{array}$ & \multirow{2}{*}{$\begin{array}{c}F(1 \\
20.134)= \\
0.199\end{array}$} & \multirow{2}{*}{$\begin{array}{c}P= \\
0.658\end{array}$} & \multirow{2}{*}{$\begin{array}{c}\mathrm{F}(1,5.714)= \\
0.056\end{array}$} & \multirow{2}{*}{$\begin{array}{c}P= \\
0.813\end{array}$} \\
\hline & Post & $\begin{array}{c}124.67 \\
\pm \\
18.63\end{array}$ & $\begin{array}{l}122.80 \\
\pm \\
22.04\end{array}$ & & & & \\
\hline \multicolumn{4}{|c|}{$\begin{array}{l}\text { Multivariate Tests Within- } \\
\text { Subjects Using Wilks' Lambda }\end{array}$} & \multirow[b]{2}{*}{$\begin{array}{l}\mathrm{F}(6,39)= \\
0.543\end{array}$} & \multirow[b]{2}{*}{$\begin{array}{c}P= \\
0.722\end{array}$} & \multirow[b]{2}{*}{$\begin{array}{l}\mathrm{F}(6,39)= \\
0.606\end{array}$} & \multirow[b]{2}{*}{$\begin{array}{c}\mathrm{P}= \\
0.724\end{array}$} \\
\hline \multicolumn{4}{|c|}{$\begin{array}{c}\text { Multivariate Tests of Within- } \\
\text { Subjects Effects Using Wilks' } \\
\text { Lambda }\end{array}$} & & & & \\
\hline
\end{tabular}


Table 3: SF- 36 Mental and Physical Composite Scores Results

\begin{tabular}{|c|c|c|c|c|c|c|c|}
\hline & & & & \multicolumn{4}{|c|}{ Test of Within-Subjects } \\
\hline \multirow{2}{*}{\multicolumn{2}{|c|}{ Measure }} & \multicolumn{2}{|c|}{$\begin{array}{l}\text { Type of Social } \\
\text { Support }\end{array}$} & \multicolumn{2}{|c|}{ Time } & \multicolumn{2}{|c|}{ Time*Social Support } \\
\hline & & High & Lower & $\mathrm{F}$ & $\begin{array}{l}\text { Signifi } \\
\text { cance }\end{array}$ & $\mathrm{F}$ & $\begin{array}{l}\text { Signifi } \\
\text { cance }\end{array}$ \\
\hline \multirow{2}{*}{$\begin{array}{c}\text { Mental } \\
\text { Compos } \\
\text { ite } \\
\text { Score }\end{array}$} & Pre & $\begin{array}{c}53.08 \\
\pm \\
10.53\end{array}$ & $\begin{array}{c}50.67 \\
\quad \pm \\
11.68\end{array}$ & \multirow{2}{*}{$\begin{array}{c}F(1, \\
26.519)= \\
0.603\end{array}$} & \multirow{2}{*}{$\begin{array}{c}\mathrm{P}= \\
0.442\end{array}$} & \multirow{2}{*}{$\begin{array}{c}\mathrm{F}(1,0.007)= \\
0.000\end{array}$} & \multirow{2}{*}{$\begin{array}{c}\mathrm{P}= \\
0.990\end{array}$} \\
\hline & Post & $\begin{array}{c}53.62 \\
\pm \\
9.46\end{array}$ & $\begin{array}{c}49.67 \\
\pm \\
14.29\end{array}$ & & & & \\
\hline \multirow{2}{*}{$\begin{array}{c}\text { Physical } \\
\text { Compos } \\
\text { ite } \\
\text { Score }\end{array}$} & Pre & $\begin{array}{l}39.19 \\
\pm \\
7.63\end{array}$ & $\begin{array}{l}36.67 \\
\pm \\
3.76\end{array}$ & \multirow{2}{*}{$\begin{array}{c}\mathrm{F}(1, \\
50.052)= \\
2.310\end{array}$} & \multirow{2}{*}{$\begin{array}{c}\mathrm{P}= \\
0.137\end{array}$} & \multirow{2}{*}{$\begin{array}{c}\mathrm{F}(1, \\
317.001)= \\
14.630\end{array}$} & \multirow{2}{*}{$\begin{array}{l}\mathrm{P}= \\
0.0001 \\
*\end{array}$} \\
\hline & Post & $\begin{array}{c}48.43 \\
\pm \\
6.03\end{array}$ & $\begin{array}{c}32.00 \\
\quad \pm \\
5.00\end{array}$ & & & & \\
\hline \multicolumn{4}{|c|}{$\begin{array}{c}\text { Multivariate Tests Within- } \\
\text { Subjects Using Wilks' Lambda }\end{array}$} & \multirow[b]{2}{*}{$\begin{array}{c}\mathrm{F}(2,36)= \\
1.736\end{array}$} & \multirow[b]{2}{*}{$\begin{array}{c}\mathrm{P}= \\
0.191\end{array}$} & \multirow[b]{2}{*}{$\begin{array}{c}\mathrm{F}(2,36)= \\
7.852\end{array}$} & \multirow[b]{2}{*}{$\begin{array}{c}\mathrm{P}= \\
0.002 *\end{array}$} \\
\hline \multicolumn{4}{|c|}{$\begin{array}{l}\text { Multivariate Tests of Within- } \\
\text { Subjects Effects Using Wilks' } \\
\text { Lambda }\end{array}$} & & & & \\
\hline
\end{tabular}

\section{*= Statistically Significant}


Table 4: SF-36 Subscale Scores Results

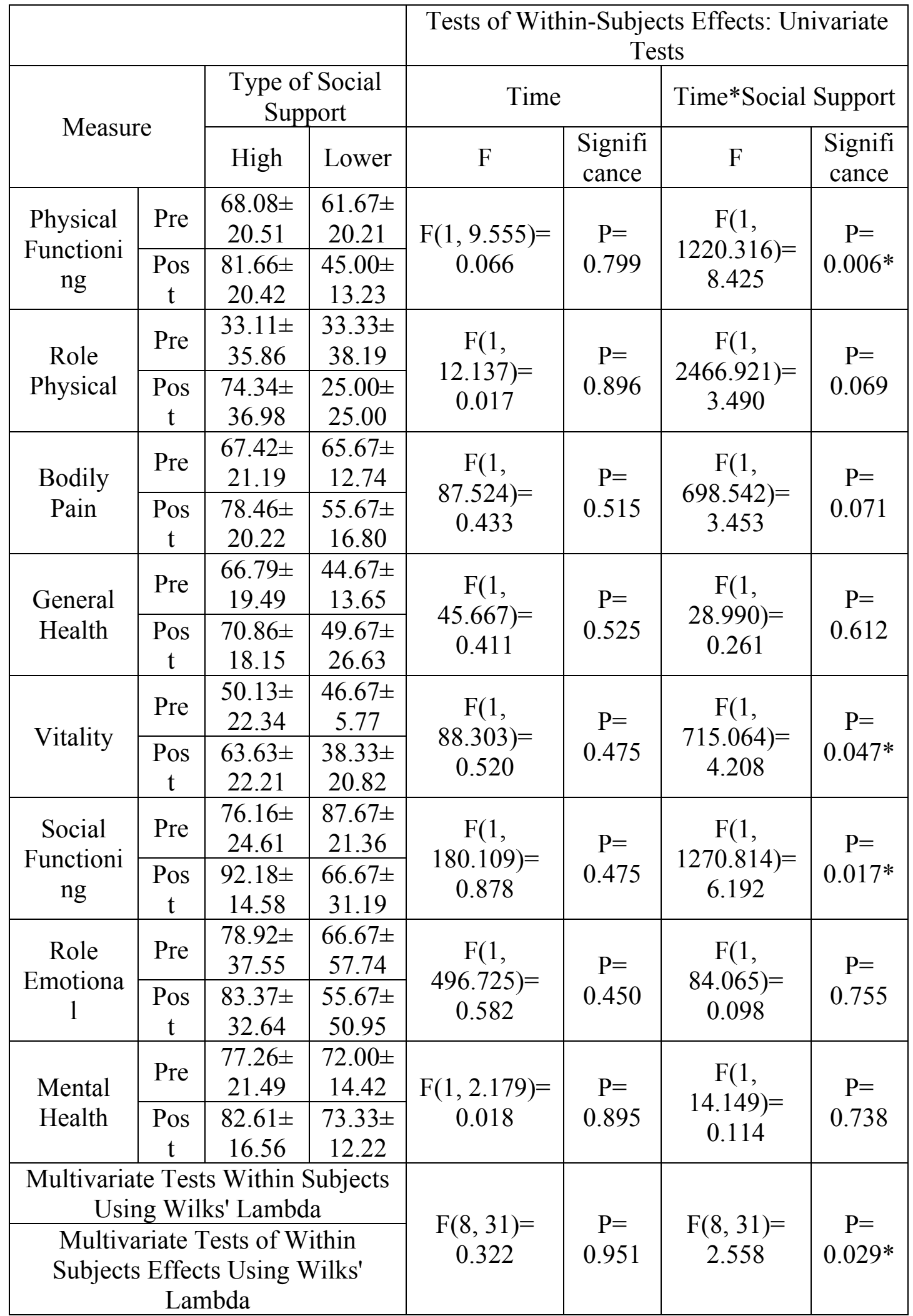


Figure 2: Pre and Post SF-36 Mental and Physical Composite Score

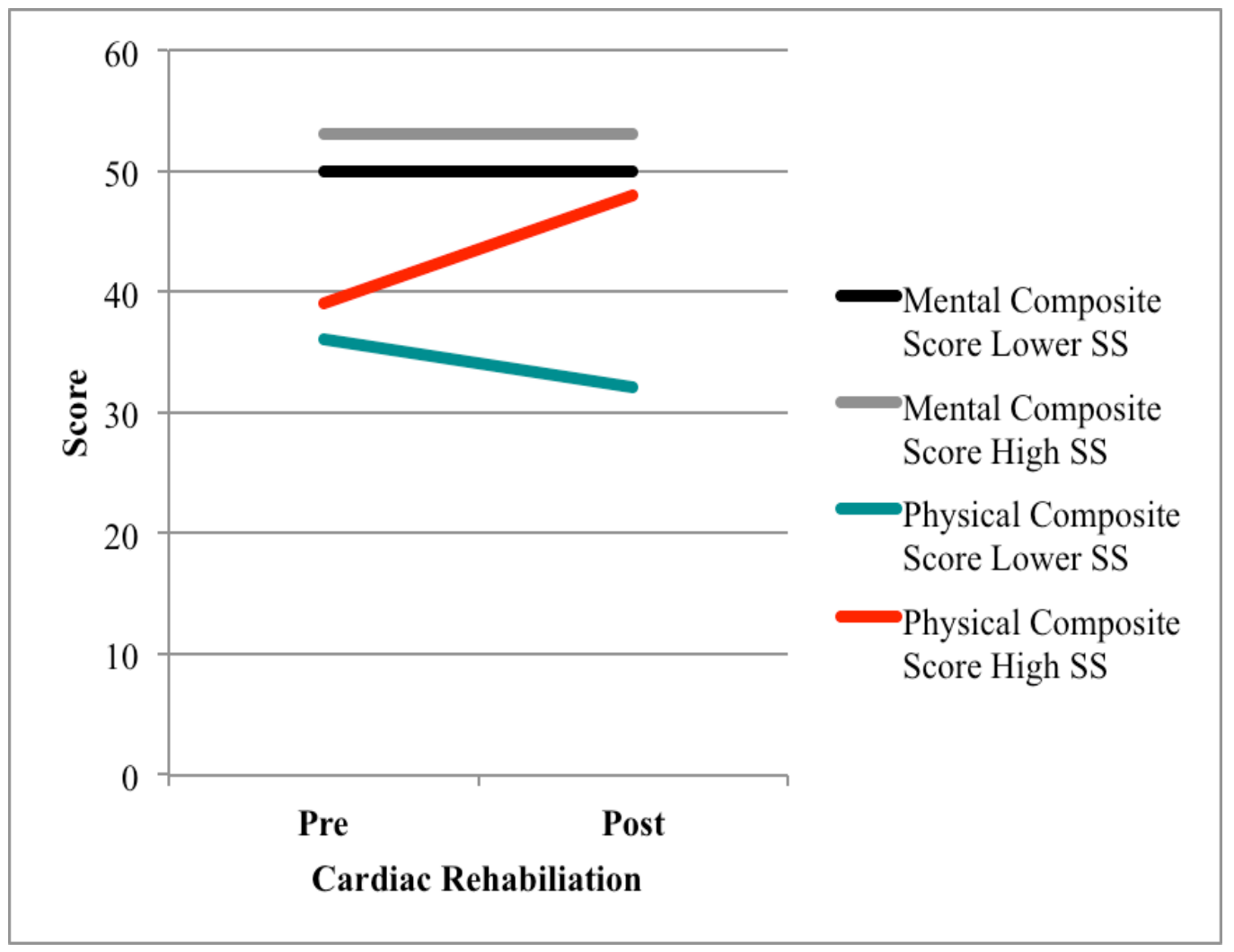


Figure 3: Pre and Post SF-36 Significant Subscale Scores

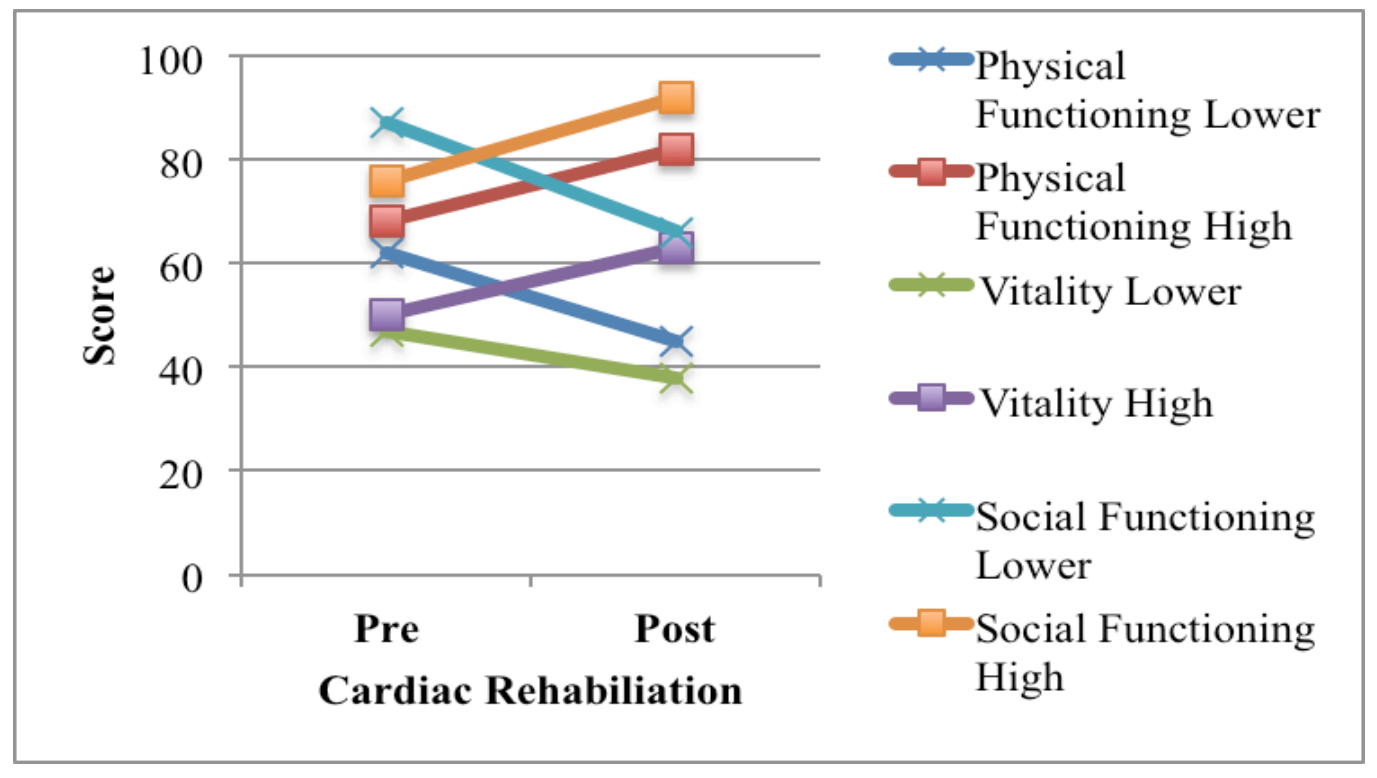




\section{CHAPTER 5}

\section{DISCUSSION}

This study examined the relationship between perceived social support on the results of 12-weeks of CR. These results suggest that level of social support did not have a statistically significant impact on measured outcomes such as anthropometric data (body mass index) or stress test results (systolic and diastolic pressures, time on treadmill and maximum attained heart rate). However, there were statistically significant results for quality of life, with the higher social support group increasing and the lower social support group decreasing. Typically women report lower levels of quality of life across all eight subcategories. Bosworth, Siegler, Olsen, et al. determined that CVD affects women at an older age, which is likely to contribute to a decreased health-related quality of life. ${ }^{62}$ For this reason, a decrease in the physical composite score, physical functioning, vitality and social functioning measures could be expected in the lower social support group due to the larger proportion of women.

This study did not find a statistically significant relationship between

anthropometrics and social support. Marcoux, Trenkner and Rosenstock ${ }^{65}$ and Aggarwal, Liao, Allegrante, et al. ${ }^{66}$ determined that social support does impact weight loss and individuals with low social support increased BMI and lowered physical activity in their study. If social support impacts weight loss than it would affect body mass index as well since body mass index is a ratio of weight to height. 
This study did not find a statistically significant relationship between stress test results and social support. Stress test results (i.e. positive, negative or inconclusive) and termination reason were not obtained. If the stress test results were obtained then an individual's time on treadmill during their test could have been explained, especially if they decreased their time on their exit test. Additionally, the participants' medication information was not obtained at any point during the study. This could have affected a participant's maximum attained heart rate, specifically if they were taking a beta-blocker. When individuals takes a beta-blocker it forces their blood vessels to open, increasing blood flow; therefore, their heart rates would be slower due to less force which would decrease their blood pressure. ${ }^{67}$

This study reported significance in health-related quality of life measures as determined by the SF-36. Specifically the scales that were impacted were the physical composite score, physical functioning, vitality and social functioning subscales. These findings are consistent with other research on perceived social support and healthrelated quality of life with CR. Riaz, Syed, O'Reilly, et al. ${ }^{68}$ showed significant improvement after $\mathrm{CR}$ in the physical composite score and no improvement in the mental composite score. Additionally, Staniute, Brozaitiene and Bunevicus ${ }^{63}$ elicited similar results in regards to perceived social support and quality of life. Their study used the Multidimensional Scale of Perceived Social Support and the SF-36. These authors determined that social support and stressful life events had an effect on quality of life, specifically social support may affect mental health, perceptions of energy and vitality and social functioning of CVD patients. ${ }^{63}$ Additionally, a question remains 
whether using a survey with a more expanded set of questions would provide a more detailed analysis of participants' actual social support.

One of the primary limitations of this study was that the majority of the participants had high levels of perceived social support as measured on the ESSI. Therefore, I artificially divided the subjects into high and lower social support groups, but the low group was not a clinically low perceived social support group.

The artificial creation of two groups using the ESSI would not affect its high test-rest raises questions about the validity of the ESSI, as used in this study. This tool was validated as a measure of social support, able to differentiate between those with high and low support. There is no empirical validity evidence supporting the creation of the two artificial groups used in this study. This lack of validity evidence may explain this study's non-significant findings: the two artificial groups were not different on social support. Consequently, caution in interpretation of the results is needed. Fortunately, the groups were created after considering the participants' responses on the utilized Likert scale. This procedure provides preliminary evidence of the content validity supporting the creation of the high and lower groups used in this study.

An additional limitation may include the honesty of participants' answer being confounded by the knowledge of being in a research study. The participants could have perceived themselves as having a sufficient or high level of social support. Other limitations include the small sample size, the high social support group had eight times more participants than the lower perceived social support group (49 to 6) and women were fewer in number thus limiting the generalizability of this data. Given the 
prevalence of CVD among older women, ${ }^{19}$ it would be important to increase their participation in order to more widely apply these results. Also, the enrolled participants were from the same CR clinic, therefore, the same geographic location, which could potentially limit the generalizability of the results to individuals with CVD and participating in CR in other locations that have a more diverse population and or different environmental stresses.

In conclusion, CR participants with high perceived social support improved their physical health, physical functioning, vitality and social functioning over 12weeks of CR when compared with a lower perceived social support group. Interestingly, those participants with lower social support decreased their physical composite score and physical functioning subscale despite improvements in their physical functioning measures. This finding is interesting considering the majority of these participants had high levels of perceived social support. Finally, assessments of social support can be effective and should be considered in CR programming. It may provide more detailed clinical information for the health care provider. 


\section{REFERENCES}

1. Roger VL, Go AS, Lloyd-Jones DM, Benjamin EJ, Berry JD, Borden WB, et al. Heart disease and stroke statistics-2012 update: a report from American Heart Association. Circulation. 2011: E1-E220.

2. What is cardiovascular disease? [Internet]. American Heart Association Incorporated; 2011 [updated 2013 August 30; cited 2012 October 16]. Available from: http://www.heart.org/ORG/Caregiver/Resources/WhatisCardiovascular Disease/What-is-CardiovascularDisease_UCM_301852_Article.jsp.

3. Carlsson AC, Wändell PE, Gigante B, Leander K, Hellenius ML, de Faire U. Seven modifiable lifestyle factors predict reduced risk for ischemic cardiovascular disease and all-cause mortality regardless of body mass index: a cohort study. Int J Cardiol. 2013;168(2):946-952.

4. Carhart RL Jr, Ades PA. Gender differences in cardiac rehabilitation. Cardiol Clin. 1998;16(1): 37-43.

5. What are my chances of getting heart disease? [Internet]. American Heart Association Incorporated; 2011 [updated 2013 April 15; cited 2012 October 16]. Available from: http://www.heart.org/HEARTORG/Conditions/More /MyHeartlandStrokeNews/What-Are-My-Chances-Of-Getting-Heart-DiseaseInfographicUCM443749_SubHomePage.jsp.

6. Boutin- Foster C. Getting to the heart of social support: a qualitative analysis of types of instrumental support that are most helpful in motivating cardiac risk factor modification. Heart Lung. 2005;34(1):22-29. 
7. Lett HS, Blumenthal JA, Babyak MA, Strauman TJ, Robins C, Sherwood A. Social support and coronary heart disease: epidemiological evidence and implications for treatment. Psychosom Med. 2005;67(6):869-878.

8. Davidson DM. Social support and cardiac rehabilitation: a review. J Cardiopulm Rehabil. 1987;7(4):196-201.

9. Dracup K. Cardiac rehabilitation: The role of social support in recovery and compliance. In: Shumaker SA, Czajkowski SM, editors. Social Support and Cardiovascular Disease. New York, NY: Plenum Press; 1994. P. 333-353.

10. Mookadam F, Arthur HM. Social support and its relationship to morbidity and mortality after acute myocardial infarction: systematic overview. Arch Intern Med. 2004;164(14):1514-1518.

11. Mattson M, Gibb Hall J. Linking health communication with social support. In: Mattson M, Gibb Hall J. Health as Communication Nexus: A Service-learning Approach. Dubuque, IA: Kendall Hunt; 2011. p. 181-218.

12. Zullo M, Dolansky M, Jackson L. Cardiac rehabilitation, health behaviors, and body mass index post-myocardial infarction. J Cardiopulm Rehabil. 2010;30(1):28-34.

13. Pullen PR, Thompson WR, Bernadot D, Jerome BL, Mehta PK, Rifai L., et al. Benefits of yoga for African American heart failure patients. Med Sci Sports Exer. 2010;42(4):651-657.

14. Aldana SG, Whitmer WR, Greenlaw R, Avins AL, Thomas D, Salberg A, et al. Effect of intense lifestyle modification and cardiac rehabilitation on psychosocial cardiovascular disease risk factors and quality of life. 
Behav Modif. 2006;30(4):507-525.

15. Compare A, Zarbo C, Manzoni GM, Castelnuovo G, Baldassari E, Bonardi A, et al. Social support, depression, and heart disease: a ten year literature review. Front Psychol. 2013;4:1-7.

16. Grace SL, Abbey SE, Shnek ZM, Irvine J, Franche RL, Stewart DE. Cardiac rehabilitation I: review of psychosocial factors. Gen Hosp Psychiat. 2002;24(3)121-126.

17. Shepard CW, While AE. Cardiac rehabilitation and quality of life: a systematic review. Int J Nurs Stud. 2012;49(6):755-771.

18. Rosamond W, Flegal K, Furie K, Go A, Greenlund K, Haase N, et al. Heart disease and stroke statistics--2008 update: a report from the American Heart Association Statistics Committee and Stroke Statistics Subcommittee. Circulation. 2008;117(4);e25-146.

19. Piscatella JC, Franklin BA. Take a load off your heart: 109 things you can actually do to prevent, halt, or reverse heart disease. New York: Workman Pub. 2003.

20. Facts About Women and Cardiovascular Disease [Internet]. American Heart Association Incorporated; 2012 [updated 2012; cited 2012 October 16]. Available from: http://www.heart.org/idc/groups/heartpublic/@wcm/@adv/documents /downloadable/ucm_302256.pdf.

21. Lavie C, Milani RV. Effects of cardiac rehabilitation programs on exercise capacity, coronary risk factors, behavioral characteristics, and quality of life in a large elderly cohort. Am J Cardiol. 1995;76(3):177-179. 
22. Christensen K, Jordan M. Pumping up cardiac rehab: exercise guidelines for postheart surgery clients. American Fitness. 2008;26(5):58-64.

23. Thompson WR. ACSM's Guidelines for Exercise Testing and Prescription. 8th ed. Philadelphia, PA:Lippincott Williams \& Wilkins; 2010.

24. Keteyian SJ, Piña IL, Hibner BA, Fleg JL. Clinical role of exercise training in the management of patients with chronic heart failure. J Cardiopulm Rehabil. 2010;30(2):67-76.

25. Glassman SJ. Components of a cardiac rehab program. Rehab Manag. 2000;13(1):28-30.

26. Hedbäck B, Perk J, Hörnblad M, Ohlsson U. Cardiac rehabilitation after coronary artery bypass surgery: 10-Year results on mortality, morbidity and readmissions to hospital. J Cardiovasc Risk. 2001;8(3):153-158.

27. Leon AS, Franklin BA, Costa F, Balady GJ, Berra KA, Stewart KJ, et al. Cardiac rehabilitation and secondary prevention of coronary heart disease: an American Heart Association scientific statement from the Council on Clinical Cardiology (Subcommittee on Exercise, Cardiac Rehabilitation, and Prevention) and the Council on Nutrition, Physical Activity, and Metabolism (Subcommittee on Physical Activity), in collaboration with the American Association of Cardiovascular and Pulmonary Rehabilitation. Circulation. 2005;111(3):369-376.

28. Duscha BD, Annex BH, Green HJ, Pippen AM, Kraus WE. Deconditioning fail to explain peripheral skeletal muscle alterations in men with chronic heart failure. J Amer Coll Cardiol. 2002;39(7):1170-1174.

29. Bray SR and Cowan H. Proxy efficacy: implications for self-efficacy and exercise 
intentions in cardiac rehabilitation. Rehabil Psychol. 2004;49(1):71-75.

30. Blum MR, Schmid JP, Eser P, Saner H. Long-term results of a 12-week comprehensive ambulatory cardiac rehabilitation program.

J Cardiopulm Rehabil. 2013;33(2):84-90.

31. Bock BC, Albrecht AE, Traficante RM, Clark MM, Pinto BM, Tilkemeier P, et al. Predictors of exercise adherence following participation in a cardiac rehabilitation program. Int J of Behav Med. 1997;4(1):60-75.

32. Caulin-Glaser T, Blum M, Schmeizl R, Prigerson HG, Zaret B, Maxure CM. Gender differences in referral to cardiac rehabilitation programs after revascularization. J Cardiopulm Rehabil. 2001;21(1):24-30.

33. Cooper AF, Jackson G, Weinman J, Horne R. Factors associated with cardiac rehabilitation attendance: a systematic review of the literature. Clin Rehabil. 2002;16(5):541-552.

34. Johnson JE, Weinert C, Richardson JK. Rural residents' use of cardiac rehabilitation programs. Public Health Nurs. 1998;15(4):288-296.

35. Evenson, KR, Fleury J. Barriers to outpatient cardiac rehabilitation participation and adherence. J Cardiopulm Rehabil. 2000;20(4):241-246.

36. Husak L, Krumholz HM, Lin ZQ, Kasl SV, Mattera JA, Roumanis SA, et al. Social support as a predictor of participation in cardiac rehabilitation after coronary artery bypass graft surgery. J Cardiopulm Rehabil. 2005;24(1):19-26.

37. Sotile WM. Psychosocial Interventions for Cardiopulmonary Patients: A Guide for Health Professionals. Champaign, IL: Human Kinetics; 1996. 38. Sorensen EA, Wang F. Social support, depression, functional status, and gender 
differences in older adults undergoing first-time coronary artery bypass graft surgery. Heart Lung. 2009; 38(4):306-317.

39. Moser DK. Social support and cardiac recovery. J Cardiovasc Nurs. 1994;9(1):27-36.

40. Albrecht TL, Adelman MB. Communication social support: A theoretical perspective. In: Albrecht TL, Adelman MB. Communicating Social Support. Newbury Park, CA: Sage; 1987. p. 18-39.

41. NCI dictionary of cancer terms [Internet]. National Cancer Institute; 2014 [cited 2014 April 19]. Available from: www.cancer.gov/dictionary.

42. Sherbourne CD, Stewart AL. The MOS Social Support Survey. Soc Sci Med. 1991;32(6):705-714.

43. Lett HS, Blumenthal JA, Babyak MA, Catellier DJ, Carney RM, Berkman LF, et al. Social support and prognosis in patients at increased psychosocial risk recovering from myocardial infarction. Health Psychol. 2007;26(4):418-427.

44. House JS, Robbins C, Metzner HL. The association of social relationships and activities with mortality: prospective evidence from the Tecumseh Community Health Study. Am J Epidemiol. 1982;116(1):123-140.

45. Litt MD, Kleppinger A, Judge JO. Initiation and maintenance of exercise behavior in older women: predictors from the social learning model. J Behav Med. 2002;25(1):83-97.

46. Wing RR, Jeffery RW. Benefits of recruiting participants with friends and increasing social support for weight loss and maintenance. $J$ Consult Clin Psych. 1999;67(1):132-138. 
47. ENRICHD Investigators. Enhancing Recovery in Coronary Heart Disease (ENRICHD) study intervention: rationale and design. Psychosom Med. 2001;63(50):747-755.

48. Fischer Aggarwal BA, Liao M, and Mosca L. Physical activity as a potential mechanism through which social support may reduce cardiovascular disease risk. J Cardiovasc Nurs. 2008;23(2):90-96.

49. Peláez S, Lavoie KL, Gordon JL, Arsenault A, Bacon SL. Social networks and exercise in coronary heart disease patients. J Cardiopulm Rehabil. 2010;30(5):324-328.

50. Uchino BN. Social Support and Physical Health: Understanding the Health Consequences of Relationships. New Haven, CT: Yale UP; 2004.

51. Antonucci TC and Akiyama H. An examination of sex differences in social support among older men and women. Sex Roles. 1987;17(11/12):737-749.

52. Goldsmith D, Lindholm KA, Bute JJ. Dilemmas of talking about lifestyle changes among couples coping with a cardiac event. Soc Sci Med. 2006;63(8):2079-2090.

53. McLean S, Timmins F. An exploration of the information needs of spouse/partner following acute myocardial infarction using focus group methodology. Nur Crit Care. 2007;12(3):141-149.

54. Cohen S, Syme SL. Issues In the Study and Application of Social Support. In: Cohen S, Syme SL, editors. Social Support and Health. San Francisco: Academic Press; 1985. p. 3-22

55. Cohen, S, Mermelstein R, Kamarck T, Hoberman HM. Measuring the functional 
components of social support. In: Sarson IG, Sarson BR, editors. Social Support: Theory, Research and Applications. Holland: Martinus Nijhoff Publisher;1985.

p. $73-94$

56. Seeman TE, Berkman LF. Structural characteristics of social networks and their relationship with social support in the elderly: who provides support. Soc Sci Med. 1988;26(7):737-749.

57. Seeman TE, Berkman LF, Blazer D, Rowe JW. Social ties and support and neuroendocrine function: the MacArthur studies of successful aging. Ann Behav Med. 1994;16(2):95-106.

58. Sarason IG, Levine HM, Basham RB, Sarason BR. Assessing social support: the social support questionnaire. J Pers Soc Psychol. 1983;44(1):127-139.

59. Mitchell PH, Powell L, Blumenthal J, Norten J, Ironson G, Pitula CR, et al. A short social support measure for patients recovering from myocardial infarction: the ENRICHD Social Support Inventory. J Cardiopulm Rehabil. 2003;23(6):398-403.

60. Mitchell PH, Powell L, Blumenthal J, Norten J, Ironson G, Pitula CR, et al. A short social support measure for patients recovering from myocardial infarction: the ENRICHD Social Support Inventory. J Cardiopulm Rehabil. 2003;23(6):398-403.

61. Beckie TM, Beckstead JW. The effects of a cardiac rehabilitation program tailored for women on their perceptions of health: a randomized clinical trial. J Cardiopulm Rehabil. 2011;31(1):25-34.

62. Bosworth HB, Siegler IC, Olsen MK, Brummett BH, Barefoot JC, Williams RB, 
et al. Social support and quality of life in patients with coronary artery disease. Qual Life Res. 2000;9(7):829-839.

63. Staniute M, Brozaitiene J, Bunevicius R. Effects of social support and stressful life events on health-related quality of life in coronary artery disease patients. J Cardiovasc Nurs. 2013;28(1):83-89.

64. Greco A, Steca P, Pozzi R, Monzni D, D’Addario M, Villani A, et al. Predicting depression from illness severity in cardiovascular disease patients: self-efficacy beliefs, illness perception, and perceived social support as mediators. Int J Behav Med. 2014;21(2):221-229.

65. Marcoux BC, Trenkner LL, Rosenstock IM. Social networks and social support in weight loss. Patient Educ Couns. 1990;15:229-238.

66. Aggarwal B, Liao M, Allegrante JP, and Mosca L. Low social support level is associated with non-adherence to diet at 1-year in the Family Intervention Trial for Heart Health (FIT Heart). J Nutr Educ Behav. 2010;42(6):380-388.

67. How do beta blocker drugs affect exercise? [Internet].: American Heart Association Incorporated; 2013 [updated 27 March 2013; cited 2014 June 2]. Available from: http://www.heart.org/HEARTORG/Conditions/More/ MyHeartandStrokeNews/How-do-beta-blocker-drugs-affect exercise UCM_450771_Article.jsp.

68. Riaz A, Syed IA, O’Reilly M, Giffney S, and Morrissey C. Impact of cardiac rehabilitation on health related quality of life. Ir Med J. 2009;102(10):331-332. 


\section{APPENDICES}

Statement of the Problem. ................................................ 58

Cardiac Rehabilitation Education Topics ....................................... 59

Measures. ............................................................. 60

Consent Forms. ............................................................. 64 


\section{STATEMENT OF THE PROBLEM}

The prevalence of CVD is rapidly increasing; therefore, increasing the number of individuals who attend CR. It is crucial to ensure that each individual achieves his or her individual goals while participating in the program. Success in the program fosters and creates close relationships and further assists the individuals who have CVD. It has been researched that individuals with close relationships may assist against further CVD complications; therefore, a research study to evaluate an individual's perceived level of social support may help to decrease their risk of CVD. Accordingly, this study was created to examine this relationship.

Primary Aim: To determine the effects of social support on an individual's result of 12-weeks of CR.

Hypothesis: Patients with higher levels of social support will decrease their body mass index, increase their stress test duration, show greater changes in their maximum attained heart rate and overall improvements in health through their SF-36 scores. 


\section{CARDIAC REHABILITATION EDUCATION TOPICS}

\section{EXERCISE}

1. Components of Exercise \& Judging Exercise Tolerance

2. Benefits of Exercise: The Reality of How Much is Enough

3. Long Term Exercise, Purchasing Home Equipment, etc.

4. Cardiac Yoga

5. Strengthening Your Core/ Functional Training

6. Resistance Training

7. Caring for Your Feet

II. CLINICAL

1. Anatomy \& Physiology of the Heart/ CABG \& Valve

2. Cardiac Medications (1\&2)

3. Treatment for Chest Pain

4. Cardiac Tests

5. Heart Failure

6. Diabetes Complications

7. Risk Factors

8. Acute Coronary Syndrome and Medications

9. Impact of Medications on Sexual Function

III. NUTRITION

1. Sodium Restriction

2. Portions

3. Diabetes: Basic Dietary Strategies

4. Dining Out

5. Low Fat Cooking

6. Fats \& Oils

7. Red Meat, Chicken \& Fish

8. Fruits, Vegetables \& Grains

9. Food Labels

\section{BEHAVIORAL PSYCHOLOGY}

1. Behavior Change (1 (Risk Factor Management) \& 2 (Weight Management))

2. How to Communicate with Your Physician

3. Psychological Reactions to Heart Disease \& the Family

4. Intimacy \& Heart Disease

5. Advanced Directives

6. Stress Management

7. Depression

8. Relaxation Techniques 
SHORT FORM-36 (SF-36)

\section{$\underline{S F}-36-1$ of 3}

DIRECTIONS: This survey asks for your views about health. This information will help keep track of how you feel and how well you are able to do your usual activities. Answer every question by filling in the appropriate circle. If you are unsure how to answer a question, please give the best answer you can.

1. In general, would you say your health is:

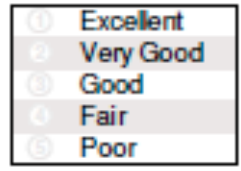

2. Compared to one year ago, how would you rate you health in general now?

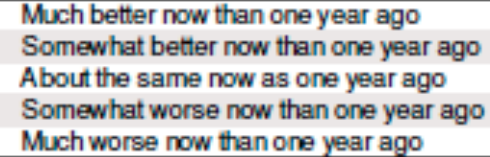

3. The following items are about activities you might do during a typical day. Does your health now limit you in these activities? $\mathrm{f}$ so, how much?

\begin{tabular}{|c|c|c|c|}
\hline & $\begin{array}{l}\text { Yes, } \\
\text { Limited a Lat }\end{array}$ & $\begin{array}{l}\text { Yes, } \\
\text { Limited a Little }\end{array}$ & $\begin{array}{l}\mathrm{Ne}, \mathrm{Nat} \\
\text { Limitad at. All }\end{array}$ \\
\hline $\begin{array}{l}\text { a. Vigorous activities, such as ruming, lifting } \\
\text { heavy objects, participating in strenuous sports. }\end{array}$ & 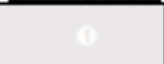 & $x^{2}$ & $\sqrt{2}$ \\
\hline $\begin{array}{l}\text { b. Mederate acfivities, such as moving a table, } \\
\text { pushing a vacuum cleaner, bowling, or playing go }\end{array}$ & & (2) & (2) \\
\hline c. Lifting or carrying groceries. & (1) & & (3) \\
\hline d. Climbing several fights of stairs. & (1) & & (9) \\
\hline e. Climbing one fight of stairs. & (1) & & a \\
\hline f. Bending, kneeling, or stooping. & (1) & & (1) \\
\hline g. Walking more than a mile. & (1) & & (9) \\
\hline h. Waking several blocks. & (1) & & (9) \\
\hline i. Waking one block. & (1) & & (9) \\
\hline j. Bathing or dressing yourself. & (1) & & (2) \\
\hline
\end{tabular}




\section{$\underline{\text { SF- }-36-2 \text { of } 3}$}

4. During the past 4 weeks, have you had any of the following problems with your work or other regular daily activities as a result of your physical health?

(Please answer YES or NO for each question by filling in the appropriate circle).

YES NO

a. Cut down on the amount of time you spent on work or other activities.

b. Accomplished less than you would like.

c. Were limited in the kind of work or other activities.

d. Had difficuty performing the work or other activities (for example, it took extra effort).

5. During the past 4 weeks, have you had any of the following problems with your work or regular daily activities as a result of any emotional problems, such as feeling depressed or anxious? (Please answer YES or NO for each question by filing in the appropriate circle).

YES NO

a. Cut down on the amount of time you spent on work or other activities.

b. Accomplished less than you would like.

c. Didn't do work or other activities as carefuly as usual.

6. During the past 4 weeks, to what extent has your physical heath or emotonal problems interfered with your nommal social activities with family, friends, neighbors or groups?

\begin{tabular}{|l|}
\hline Not at al \\
Slightly \\
Moderately \\
Quite a bit \\
Extremely \\
\hline
\end{tabular}

7. How much bodily pain have you had during the past 4 weeks?

\begin{tabular}{|l|}
\hline None \\
Very Mild \\
Mild \\
Moderate \\
Severe \\
Very Severe \\
\hline
\end{tabular}

8. During the past 4 weeks, how much did pain interfere with your normal work (including both work outside the home and housework)?

Not at al

A little bit

Moderately

Quite a bit

Extremely

ID: $\quad$ E: I:

CB Pago 5 of 8 
$\underline{\mathrm{SF}-36-3 \text { of } 3}$

9. These questions are about how you feel and how things have been with you during the past 4 weeks. For each question, please give the answer that comes closest to the way you have been feeling.

\begin{tabular}{|l|l|l|l|l|l|l|}
\cline { 2 - 7 } \multicolumn{1}{c|}{$\begin{array}{c}\text { How much of the time } \\
\text { during the past 4 weeks... }\end{array}$} & $\begin{array}{c}\text { All } \\
\text { of the } \\
\text { fime }\end{array}$ & $\begin{array}{c}\text { Most } \\
\text { of the } \\
\text { time }\end{array}$ & $\begin{array}{c}\text { A good } \\
\text { bit of } \\
\text { the time }\end{array}$ & $\begin{array}{c}\text { Some } \\
\text { of the } \\
\text { time }\end{array}$ & $\begin{array}{c}\text { A Ittle } \\
\text { of the } \\
\text { time }\end{array}$ & $\begin{array}{c}\text { None } \\
\text { of the } \\
\text { time }\end{array}$ \\
\hline a. Did you feel full of pep? & & & & & & \\
\hline $\begin{array}{l}\text { b. Have you been a very nervous } \\
\text { person? }\end{array}$ & & & & & & \\
\hline $\begin{array}{l}\text { c. Have you felt so down in the dumps } \\
\text { that nothing could cheer you up? }\end{array}$ & & & & & & \\
\hline d. Have you fet calm and peaceful? & & & & & & \\
\hline e. Did you have a lot of energy? & & & & & & \\
\hline f. Have you felt downhearted and blue? & & & & & & \\
\hline g. Did you feel worn out? & & & & & & \\
\hline h. Have you been a happy person? & & & & & & \\
\hline i. Did you feel tired? & & & & & & \\
\hline
\end{tabular}

10. During the past 4 weeks, how much of the time has your physical haalther emotional problams irterfered with your social activities (Ike visiting with friends, relatives, etc.)?

All of the time
Most of the time
Some of the time
A little of the time
None of the time

11. How true or false is each of the following statements for you?

\begin{tabular}{|l|l|l|l|l|l|}
\cline { 2 - 6 } \multicolumn{1}{c|}{} & $\begin{array}{c}\text { Definitely } \\
\text { True }\end{array}$ & $\begin{array}{c}\text { Mostly } \\
\text { True }\end{array}$ & $\begin{array}{c}\text { Dont } \\
\text { Know }\end{array}$ & $\begin{array}{c}\text { Mostly } \\
\text { False }\end{array}$ & $\begin{array}{c}\text { Defiritely } \\
\text { False }\end{array}$ \\
\hline $\begin{array}{l}\text { a. Iseem to get sick a little easier } \\
\text { than other people. }\end{array}$ & & & & & \\
\hline b. Iam as healthy as anybody lknow. & & & & & \\
\hline c. Iexpect my health to get worse. & & & & & \\
\hline d. My health is excellert & & & & & \\
\hline
\end{tabular}

ID: E: I:

$C B$ Prog 6 a $s$ 


\section{ADULT CONSENT FORM}

IRB Approval: 6/13/2013

IRB Accepted: 6/28/2013

IRB Expiration: 6/12/2014

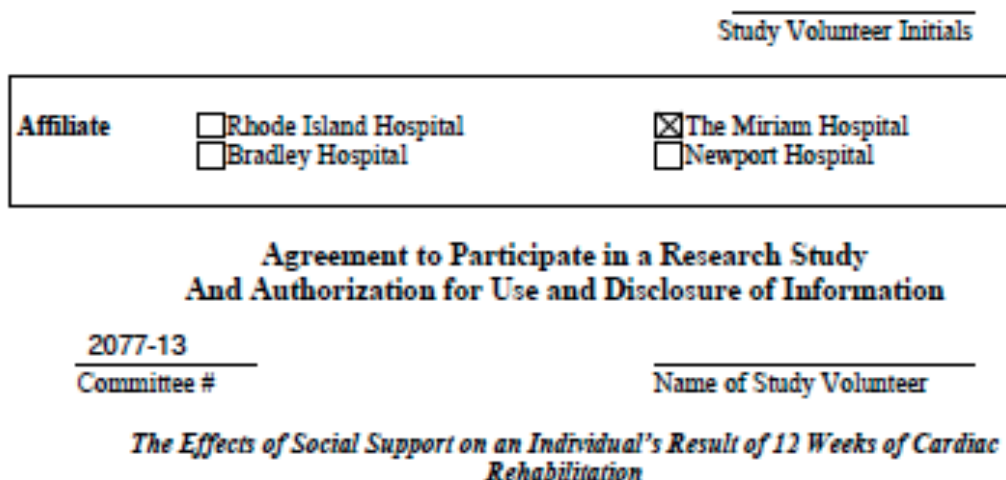

You are being asked to take part in a research study. All research studies at Lifespan hospitals follow the rules of the state of Rhode Island, the United States government and Lifespan. Before you decide whether to be in the study, you and the researcher will engage in the "informed consent" process. During this process, the researcher will explain the purpose of the study, how it will be carried out, and what you will be expected to do if you participate. The researcher will also explain the possible risks and benefits of being in the study, and will provide other information. You should feel free to ask any questions you might have. The purpose of these discussions is for you to decide whether participating in the study is the best decision for you.

If you decide to be in the study, you will be asked to sign and date this form in front of the person who explained the study to you. This form summarizes the information you discussed. You will be given a copy of this form to keep.

\section{Nature and Purpose of the Study}

You are being asked to talke part in a research project because we are examining the effects of social support on an individual's result of cardiac rehabilitation.

Cardiovascular disease is one of the leading causes of death in the United States. Many of the deaths could have been prevented with a healthy lifestyle that can increase the longevity of an individual. If an individual decreases their modifiable risk factors (i.e. cholesterol, blood pressure, physical inactivity, obesity, smoking, and diabetes) than they will increase their longevity. Modifiable risk factors can be changed through health behavior modification. Health behavior modification is a process that requires a tremendous amount of commitment from the patient and their social support. An individual's social support can protect against unnecessary stressors and assists in the behavior modification process and ultimately decrease their risk of cardiovascular disease.

The study will talke place at The Miriam Hospital Center for Cardiac Fitness in Providence, Rhode Island. The study will focus on the patients perceived level of social support on their

RPO-Adult IC and Aath -4-2012[2] 
results of cardiac rehabilitation. It will combine physical activity, nutritional education, behavioral medicine education, as well as, cardiac education. The collection of data will be collected over several months once the study is approved. The focus of this study is on an individual's perceived level of social support and their results after 12-weeks of cardiac rehabilitation.

We expect to enroll 100 patients into this study. All of the participants of this study will be participating in the same cardiac rehabilitation program and are being offered the same amount of resources.

\section{Explanation of Procedures}

If you decide to enroll in the research study than you will continue to participate in your scheduled cardiac rehabilitation exercise and education class. Your participation in the program will not be hindered if you choose not to participate in the research study. The entire study will take place at the Center for Cardiac Fitness. Once all of your pre-cardiac rehabilitation paperwork and stress test has been completed and you agree to participate in this study then your data will be viewed and analyzed accordingly. The study will be looking at your gender, height, weight, body mass index, stress test results, maximum heart rate, blood pressure results, diagnosis, catheter report, lipid profile, diabetes and attendance of the program.

Costs for participating in this study

There is no additional cost to participate in this research study

\section{Contact Information}

If you ever have any questions please call Dr. Peter Tilkemeier, who can be reached at 401-7937191 and ptillsemeier@lifespan.org or Danika Korpacz, who can be reached at 401-793-5810 and dkorpacz@lifespan org

\section{Discomforts and Risks}

During this research study you should not experience any discomforts or risks. If you ever feel as though you are, please speak to either your case manager or Dr. Tillkemeier.

\section{Benefits}

During this research study you will not incur any additional benefits other than the ones from participating in cardiac rehabilitation.

5. Alternative Therapies

If you choose not to participate in this study then you can continue to participate in cardiac rehabilitation. Regardless of your decision, you will receive the same treatment that you would receive if you participate in this stady.

\section{Refusal/Withdrawal}

It is up to you whether you want to be in the study. You are not required to enroll or participate. If you decide to participate, you can always change your mind and quit at any time. If you decide not to be in the study, or if you quit later, you will still be able to get the health care

RPO-Adult IC and Aath - 4-2012[3] 
services you normally get. If you join, but later on the researcher or your doctor feels being in the study is no longer good for you, they may choose to take you out of the study before it is over. If new information becomes available that might change your mind about whether you want to stay in the study the researcher will share this information with you as soon as possible. You will be terminated from the study if you un-enroll, do not complete the full 12 weeks, do not participate in both a pre and post cardiac rehabilitation stress test, or complete all of the necessary paperwork (i.e. cardiac rehabilitation questionnaires, consent form, and clinical symptom checklist). If you choose to withdraw from the research study you will not be penalized nor will your treatment in cardiac rehabilitation be effected. If you wish to terminate your participation in the research study then please speak with your case manager who will notify the research personnel.

\section{Medical Treatment/Pavment in Case of Injury}

A research injury is any physical or mental injury or illness caused by being in the study. If you are injured by a medical treatment or procedure you would have received even if you were not in the study that is not a research injury. To help avoid research injury and added medical expenses, it is very important to follow all study directions carefully. If you do experience a research injury, Lifespan or the study doctor can arrange medical treatment for you. Such treatment will be paid for as described below.

If you have insurance and have a research injury that is not covered by the stady, it is possible that some or all of the cost of treating you could be billed to your insurer. If your health insurance will not cover such costs, it is possible you would have to pay out of pocket. In some cases, Lifespan might be able to help you pay if you qualify for free care under Lifespan policy. However, Lifespan has no policy to cover payment for such things as lost wages, expenses other than medical care, or pain and suffering

\section{Rights and Complaints}

Signing this form does not take away any of your lawful rights. If you have any complaints about this study, or would like more facts about the rules for research studies, or the rights of people who take part in research studies you may contact Patricia E. Houser, in the Lifespan Office of Research Administration, at (401) 444-6246

\section{Confidentiality and Research Authorization for Use and Disclosure of Your Health Care} Information

Your research records will be treated as private health care records and will be protected according to Lifespan privacy practices and policies that are based on state and federal law. In particular, federal law requires us to get your permission to use or disclose (release your information to someone outside of Lifespan) your health information for research purposes. If you sign this form you agree to be in this research stady and you permit the use and disclosure of your health information for the purpose of conducting the research, providing treatment, collecting payment and running the business of the hospital.. This permission has no expiration date. You may withdraw from the study at any time. However, if you do not want the researchers to use or disclose any further information in this study you must cancel permission in writing and may do so at any time. If you cancel your permission, you will stop taking part in the 
study and no new information will be collected about you. However, if you cancel your permission, it will not apply to actions already talsen or information already collected about you by the hospital or the researchers before you canceled your permission.

Generally, the entire research record and any medical records held by the hospital may be used and released but in this research study we will only be viewing height, weight, body mass index, blood pressure results, stress test results, medications, diagnosis, gender, lipid profile, attendance record, scores to the social support survey and overall health survey for research purposes. The following people or businesses/companies/might use, release, or receive such information:

- The researcher and their support staff, including Dr. Peter Tillkemeier of The Miriam Hospital Center for Cardiac Fitness, Danika Korpacz Master's Degree Student at the University of Rhode Island, Dr. Linda Lamont, Dr. Brian Blissmer, and Dr. Susan Roush of the Kinesiology and Physical Therapy Department at the University of Rhode Island

- Dr. Lamont, Dr. Blissmer, and Dr. Roush will not be looking at the data until all pre and post cardiac rehabilitation data has been collected and fully deidentified.

- Upon being deidentified the data will be transported to the University of Rhode Island to be statistically analyzed.

- The study sponsor not applicable

- Doctors, nurses, laboratories and others who provide services to you in connection with this study.

- The company or section of the U.S. government that is paying for the study and others they hire to oversee, administer, or conduct the research:

- The United States Food and Drug Administration, the Department of Health and Human Services, the Office of Inspector General, and the Office of Civil Rights;

- People who volumteer to be patient advocates or research volunteer protectors:

- Members of the hospital's administrative staff responsible for reviewing, approving and administering clinical trials and other healthcare or research activities.

There are times when the law might require or permit Lifespan to release your health information without your permission. For example, Rhode Island law requires researchers and health care workers to report abuse or neglect of children to the Department of Children, Youth and Families (DCYF) and to report abuse or neglect of people age 60 and older to the Department of Elderly Affairs.

All researchers and health care providers are required to protect the privacy of your health care information. Other people and businesses/organizations that are not health care providers are not required by law to do that so it is possible they might re-release your information.

You have the right to refuse to sign this form and not participate in the research. Your refusal would have no affect on your treatment, charges billed to you, or benefits at any Lifespan health care site. If you do not sign, you will not be able to enroll in the research study and will not receive treatment as a study participant. 


\section{Study Volunteer Initials}

If you decide to quit the study after signing this form (as described in Section 6) no new information will be collected about you unless you gave us permission to do so. However, the hospital or the researchers may continue to use information that was collected before you quit the study to complete analysis and reports of this research.

For more detail about your privacy rights see the Lifespan Joint Privacy Notice which has or will be given to you.

\section{SIGNATURE}

I have read this informed consent and authorization form. ALL OF MV QUESTIONS HAVE BEEN ANSWERED, AND I WANT TO TAKE PART IN THIS RESEARCH STUDY.

By signing below, I give my pennission to participate in this research study and for the described uses and releases of information. I aiso conffrm that $I$ have been now or proviously grien $a$ copy of the Lifespan Privacy Notice

This informed consent document expires on $\quad 6 / 12 / 2014$

DO NOT sign this document after this expiration date

$\overline{\text { Signature of study vohunteer/authorized representative }}{ }^{*} \quad \overline{\text { Date }}$ and $\overline{\text { Time when signed }}$

I WAS PRESENT DURMNG THE CONSENT PROCESS AND SIGNING OF THIS AGREEMENT BY THE STUDY VOLUNTEER OR AUTHORIZED REPRESENTATIVE

Signature of witnes5 (required if consent

Date

is presented orally or at the request of the IRB)

I HAVE FULLY EXPLAINED TO THE ABOVE STUDY VOLUNTEER/AUTHORIZED

REPRESENTATTVE, THE NATURE AND PURPOSE, PROCEDURES. AND THE

POSSIBLE RISKS/BENEFITS OF THIS RESEARCH STUDY.

Signature of researcher or designate $\quad \overline{\text { Date }}$ and Time when signed

* If signed by agent other than study volunteer, please explain below.

RPO-Adalt IC and Aath - -2012[3]

Fiflects of Sactal Suppoert on the Results af Cardiac Rehat

May 2013 
Study Volunteer Initials

Documentation that a copy of this Informed Consent was given to the research participant is a Federal requirement. Prior to malcing a copy of the signed and dated Informed Consent please check appropriate bor(es) as applicable to indicate copy provided to: $\square$ Study Volunteer $\square$ Medical Record $\square$ Researcher $\square$ Other (Specify)

RP-Adult IC ind A th $-4-2012$ (3) 


\section{BIBLIOGRAPHY}

Aggarwal B, Liao M, Allegrante JP, and Mosca L. Low social support level is associated with non-adherence to diet at 1-year in the Family Intervention Trial for Heart Health (FIT Heart). Journal of Nutrition Education and Behavior. 2010;42(6):380-388.

Albrecht TL, Adelman MB. Communication social support: A theoretical perspective. In: Albrecht TL, Adelman MB. Communicating Social Support. Newbury Park, CA: Sage; 1987. p. 18-39.

Aldana SG, Whitmer WR, Greenlaw R, Avins AL, Thomas D, Salberg A, et al. Effect of intense lifestyle modification and cardiac rehabilitation on psychosocial cardiovascular disease risk factors and quality of life. Behavior Modification. 2006;30(4):507-525.

Frank AM, McConnell TM, Rawson ES and Fradkin A. Clinical and functional predictors of health-related quality of life during cardiac rehabilitation. Journal of Cardiopulmonary Rehabiliation and Prevention. 2011;31:223-229.

Antonucci TC and Akiyama H. An examination of sex differences in social support among older men and women. Sex Roles. 1987;17(11/12):737-749.

Beckie TM, Beckstead JW. The effects of a cardiac rehabilitation program tailored for women on their perceptions of health: a randomized clinical trial. Journal of Cardiopulmonay Rehabiliation and Prevention. 2011;31(1):25-34.

Blum MR, Schmid JP, Eser P, Saner H. Long-term results of a 12-week comprehensive ambulatory cardiac rehabilitation program. Journal of 
Cardiopulmonary Rehabilitation and Prevention. 2013;33(2):84-90.

Bock BC, Albrecht AE, Traficante RM, Clark MM, Pinto BM, Tilkemeier P, et al. Predictors of exercise adherence following participation in a cardiac rehabilitation program. International Journal of Behavioral Medicine. 1997;4(1):60-75.

Bosworth HB, Siegler IC, Olsen MK, Brummett BH, Barefoot JC, Williams RB, et al. Social support and quality of life in patients with coronary artery disease. Quality of Life Research. 2000;9(7):829-839.

Boutin- Foster C. Getting to the heart of social support: a qualitative analysis of types of instrumental support that are most helpful in motivating cardiac risk factor modification. Heart \& Lung. 2005;34(1):22-29.

Bray SR and Cowan H. Proxy efficacy: implications for self-efficacy and exercise intentions in cardiac rehabilitation. Rehabilitation Psychology. 2004;49(1):71-75.

Carhart RL Jr, Ades PA. Gender differences in cardiac rehabilitation. Cardiology Clinics. 1998;16(1): 37-43.

Carlsson AC, Wändell PE, Gigante B, Leander K, Hellenius ML, de Faire U. Seven modifiable lifestyle factors predict reduced risk for ischemic cardiovascular disease and all-cause mortality regardless of body mass index: a cohort study. International Journal of Cardiology. 2013;168(2):946-952.

Caulin-Glaser T, Blum M, Schmeizl R, Prigerson HG, Zaret B, Maxure CM. Gender differences in referral to cardiac rehabilitation programs after revascularization. Journal of Cardiopulmonary Rehabilitation and Prevention. 
2001;21(1):24-30.

Christensen K, Jordan M. Pumping up cardiac rehab: exercise guidelines for postheart surgery clients. American Fitness. 2008;26(5):58-64.

Cohen, S, Mermelstein R, Kamarck T, Hoberman HM. Measuring the functional components of social support. In: Sarson IG, Sarson BR, editors. Social Support: Theory, Research and Applications. Holland: Martinus Nijhoff Publisher;1985. p. 73-94

Cohen S, Syme SL. Issues In the Study and Application of Social Support. In: Cohen S, Syme SL, editors. Social Support and Health. San Francisco: Academic Press;1985. p. 3-22

Compare A, Zarbo C, Manzoni GM, Castelnuovo G, Baldassari E, Bonardi A, et al. Social support, depression, and heart disease: a ten year literature review. Frontiers in Psychology. 2013;4:1-7.

Cooper AF, Jackson G, Weinman J, Horne R. Factors associated with cardiac rehabilitation attendance: a systematic review of the literature. Clinical Rehabilitation. 2002;16(5):541-552.

Davidson DM. Social support and cardiac rehabilitation: a review. Journal of Cardiopulmonary Rehabilitation and Prevention. 1987;7(4):196-201.

Dracup K. Cardiac rehabilitation: The role of social support in recovery and compliance. In: Shumaker SA, Czajkowski SM, editors. Social Support and Cardiovascular Disease. New York, NY: Plenum Press; 1994. P. 333-353. Duscha BD, Annex BH, Green HJ, Pippen AM, Kraus WE. Deconditioning fail 
to explain peripheral skeletal muscle alterations in men with chronic heart failure. Journal of the American College of Cardiology. 2002;39(7):1170-1174

ENRICHD Investigators. Enhancing Recovery in Coronary Heart Disease (ENRICHD) study intervention: rationale and design. Psychosomatic Medicine. 2001;63(50):747-755.

Evenson, KR, Fleury J. Barriers to outpatient cardiac rehabilitation participation and adherence. Journal of Cardiopulmonary Rehabilitation and Prevention. 2000;20(4):241-246.

Facts About Women and Cardiovascular Disease [Internet]. American Heart Association Incorporated; 2009 [updated ; cited 2012 October 16]. Available from: http://www.heart.org/idc/groups/heartpublic/@wcm/@adv/documents /downloadable/ucm_302256.pdf.

Fischer Aggarwal BA, Liao M, and Mosca L. Physical activity as a potential mechanism through which social support may reduce cardiovascular disease risk. Journal of Cardiovascular Nursing. 2008;23(2):90-96.

Glassman SJ. Components of a cardiac rehab program. Rehab Management. 2000;13(1):28-30.

Goldsmith D, Lindholm KA, Bute JJ. Dilemmas of talking about lifestyle changes among couples coping with a cardiac event. Social Science \& Medicine. 2006;63(8):2079-2090.

Grace SL, Abbey SE, Shnek ZM, Irvine J, Franche RL, Stewart DE. Cardiac rehabilitation I: review of psychosocial factors. General Hospital Psychiatry. 
2002;24(3)121-126.

Greco A, Steca P, Pozzi R, Monzni D, D’Addario M, Villani A, et al. Predicting depression from illness severity in cardiovascular disease patients: selfefficacy beliefs, illness perception, and perceived social support as mediators. International Journal of Behavioral Medicine. 2014;21(2):221-229.

Hedbäck B, Perk J, Hörnblad M, Ohlsson U. Cardiac rehabilitation after coronary artery bypass surgery: 10-Year results on mortality, morbidity and readmissions to hospital. Journal of Cardiovascular Risk. 2001;8(3):153158.

House JS, Robbins C, Metzner HL. The association of social relationships and activities with mortality: prospective evidence from the Tecumseh Community Health Study. American Journal of Epidemiology. 1982;116(1):123-140.

How do beta blocker drugs affect exercise? [Internet].: American Heart Association Incorporated; 2013 [updated 27 March 2013; cited 2014 June 2]. Available from: http://www.heart.org/HEARTORG/Conditions/More/ MyHeartandStrokeNews/How-do-beta-blocker-drugs-affect exercise UCM_450771_Article.jsp.

Husak L, Krumholz HM, Lin ZQ, Kasl SV, Mattera JA, Roumanis SA, et al. Social support as a predictor of participation in cardiac rehabilitation after coronary artery bypass graft surgery. Journal of Cardiopulmonary Rehabilitation and Prevention. 2005;24(1):19-26.

Johnson JE, Weinert C, Richardson JK. Rural residents' use of cardiac rehabilitation programs. Public Health Nursing. 1998;15(4):288-296. 
Keteyian SJ, Piña IL, Hibner BA, Fleg JL. Clinical role of exercise training in the management of patients with chronic heart failure. Journal of Cardiopulmonary Rehabilitation and Prevention. 2010;30(2):67-76.

Lavie C, Milani RV. Effects of cardiac rehabilitation programs on exercise capacity, coronary risk factors, behavioral characteristics, and quality of life in a large elderly cohort. American Journal of Cardiology. 1995;76(3):177-179.

Leon AS, Franklin BA, Costa F, Balady GJ, Berra KA, Stewart KJ, et al. Cardiac rehabilitation and secondary prevention of coronary heart disease: an American Heart Association scientific statement from the Council on Clinical Cardiology (Subcommittee on Exercise, Cardiac Rehabilitation, and Prevention) and the Council on Nutrition, Physical Activity, and Metabolism (Subcommittee on Physical Activity), in collaboration with the American Association of Cardiovascular and Pulmonary Rehabilitation. Circulation. 2005;111(3):369376.

Lett HS, Blumenthal JA, Babyak MA, Catellier DJ, Carney RM, Berkman LF, et al. Social support and prognosis in patients at increased psychosocial risk recovering from myocardial infarction. Health Psychology. 2007;26(4):418427.

Lett HS, Blumenthal JA, Babyak MA, Strauman TJ, Robins C, Sherwood A. Social support and coronary heart disease: epidemiological evidence and implications for treatment. Psychosomatic Medicine. 2005;67(6):869-878.

Litt MD, Kleppinger A, Judge JO. Initiation and maintenance of exercise 
behavior in older women: predictors from the social learning model. Journal of Behavioral Medicine. 2002;25(1):83-97.

Marcoux BC, Trenkner LL, Rosenstock IM. Social networks and social support in weight loss. Patient Education and Counseling. 1990;15:229-238.

Mattson M, Gibb Hall J. Linking health communication with social support. In: Mattson M, Gibb Hall J. Health as Communication Nexus: A Service-learning Approach. Dubuque, IA: Kendall Hunt; 2011. p. 181-218.

McLean S, Timmins F. An exploration of the information needs of spouse/partner following acute myocardial infarction using focus group methodology. British Association of Critical Care Nurses, Nursing in Critical Care. 2007;12(3):141-149.

Mitchell PH, Powell L, Blumenthal J, Norten J, Ironson G, Pitula CR, et al. A short social support measure for patients recovering from myocardial infarction: the ENRICHD Social Support Inventory. Journal of Cardiopulmonary Rehabilitation and Prevention. 2003;23(6):398-403.

Mookadam F, Arthur HM. Social support and its relationship to morbidity and mortality after acute myocardial infarction: systematic overview. Archives of Internal Medicine. 2004;164(14):1514-1518.

Moser DK. Social support and cardiac recover. Journal of Cardiovascular Nursing. 1994;9(1):27-36.

NCI dictionary of cancer terms [Internet]. National Cancer Institute; 2014 [cited 2014 April 19]. Available from: www.cancer.gov/dictionary.

Peláez S, Lavoie KL, Gordon JL, Arsenault A, Bacon SL. Social networks and 
exercise in coronary heart disease patients. Journal of Cardiopulmonary Rehabilitation and Prevention. 2010;30(5):324-328.

Piscatella JC, Franklin BA. Take a load off your heart: 109 things you can actually do to prevent, halt, or reverse heart disease. New York: Workman Pub. 2003.

Procidano ME and Heller K. Measures of perceived social support from friends and family: three validation studies. American Journal of Community Psychology. 1983;11(1):1-24.

Pullen PR, Thompson WR, Bernadot D, Jerome BL, Mehta PK, Rifai L., et al. Benefits of yoga for African American heart failure patients. Medicine \& Science in Sports \& Exercise. 2010;42(4):651-657.

Riaz A, Syed IA, O'Reilly M, Giffney S, and Morrissey C. Impact of cardiac rehabilitation on health related quality of life. Irish Medical Journal. 2009;102(10):331-332

Roger VL, Go AS, Lloyd-Jones DM, Benjamin EJ, Berry JD, Borden WB. Heart Disease and stroke statistics-2012 update: a report from American Heart Association. Circulation. 2011: E1-E220.

Rosamond W, Flegal K, Furie K, Go A, Greenlund K, Haase N, et al. Heart disease and stroke statistics--2008 update: a report from the American Heart Association Statistics Committee and Stroke Statistics Subcommittee. Circulation. 2008;117(4);e25-146.

Sarason IG, Levine HM, Basham RB, Sarason BR. Assessing social support: the social support questionnaire. Journal of Personality and Social Psychology. 
1983;44(1):127-139.

Seeman TE, Berkman LF. Structural characteristics of social networks and their relationship with social support in the elderly: who provides support. Social Science \& Medicine. 1988;26(7):737-749.

Seeman TE, Berkman LF, Blazer D, Rowe JW. Social ties and support and neuroendocrine function: the MacArthur studies of successful aging. Annals of Behavioral Medicine. 1994;16(2):95-106.

Shepard CW, While AE. Cardiac rehabilitation and quality of life: a systematic review. International Journal of Nursing Studies. 2012;49(6):755-771.

Sherbourne CD, Stewart AL. The MOS Social Support Survey. Social Science and Medicine. 1991;32(6):705-714.

Sorensen EA, Wang F. Social support, depression, functional status, and gender differences in older adults undergoing first-time coronary artery bypass graft surgery. Heart \& Lung. 2009; 38(4):306-317.

Sotile WM. Psychosocial Interventions for Cardiopulmonary Patients: A Guide for Health Professionals. Champaign, IL: Human Kinetics; 1996.

Staniute M, Brozaitiene J, Bunevicius R. Effects of social support and stressful life events on health-related quality of life in coronary artery disease patients. Journal of Cardiovascular Nursing. 2013;28(1):83-89.

Thompson WR. ACSM's Guidelines for Exercise Testing and Prescription. 8th ed. Philadelphia, PA: Lippincott Williams \& Wilkins; 2010.

What are my chances of getting heart disease? [Internet]. American Heart 
Association Incorporated; 2011 [updated 2013 April 15; cited 2012 October

16]. Available from: http://www.heart.org/HEARTORG/Conditions/More /MyHeartlandStrokeNews/What-Are-My-Chances-Of-Getting-Heart-DiseaseInfographicUCM443749_SubHomePage.jsp.

What is cardiovascular disease? [Internet]. American Heart Association Incorporated; 2011 [updated 2013 August 30; cited 2012 October 16]. Available from: http://www.heart.org/ORG/Caregiver/Resources/ WhatisCardiovascularDisease/What-is-CardiovascularDisease UCM_301852_Article.jsp.

Wing RR, Jeffery RW. Benefits of recruiting participants with friends and increasing social support for weight loss and maintenance. Journal of Consulting and Clinical Psychology. 1999;67(1):132-138.

Uchino BN. Social Support and Physical Health: Understanding the Health Consequences of Relationships. New Haven, CT: Yale UP; 2004.

Zullo M, Dolansky M, Jackson L. Cardiac rehabilitation, health behaviors, and body mass index post-myocardial infarction. Journal of Cardiopulmonary Rehabilitation and Prevention. 2010;30(1):28-34. 